\title{
Robotic versus open radical cystectomy for bladder cancer in adults
} (Review)

Rai BP, Bondad J, Vasdev N, Adshead J, Lane T, Ahmed K, Khan MS, Dasgupta P, Guru K, Chlosta $\mathrm{PL}$, Aboumarzouk OM

Rai BP, Bondad J, Vasdev N, Adshead J, Lane T, Ahmed K, Khan MS, Dasgupta P, Guru K, Chlosta PL, Aboumarzouk OM. Robotic versus open radical cystectomy for bladder cancer in adults.

Cochrane Database of Systematic Reviews 2019, Issue 4. Art. No.: CD011903.

DOI: 10.1002/14651858.CD011903.pub2.

www.cochranelibrary.com 
TABLE OF CONTENTS

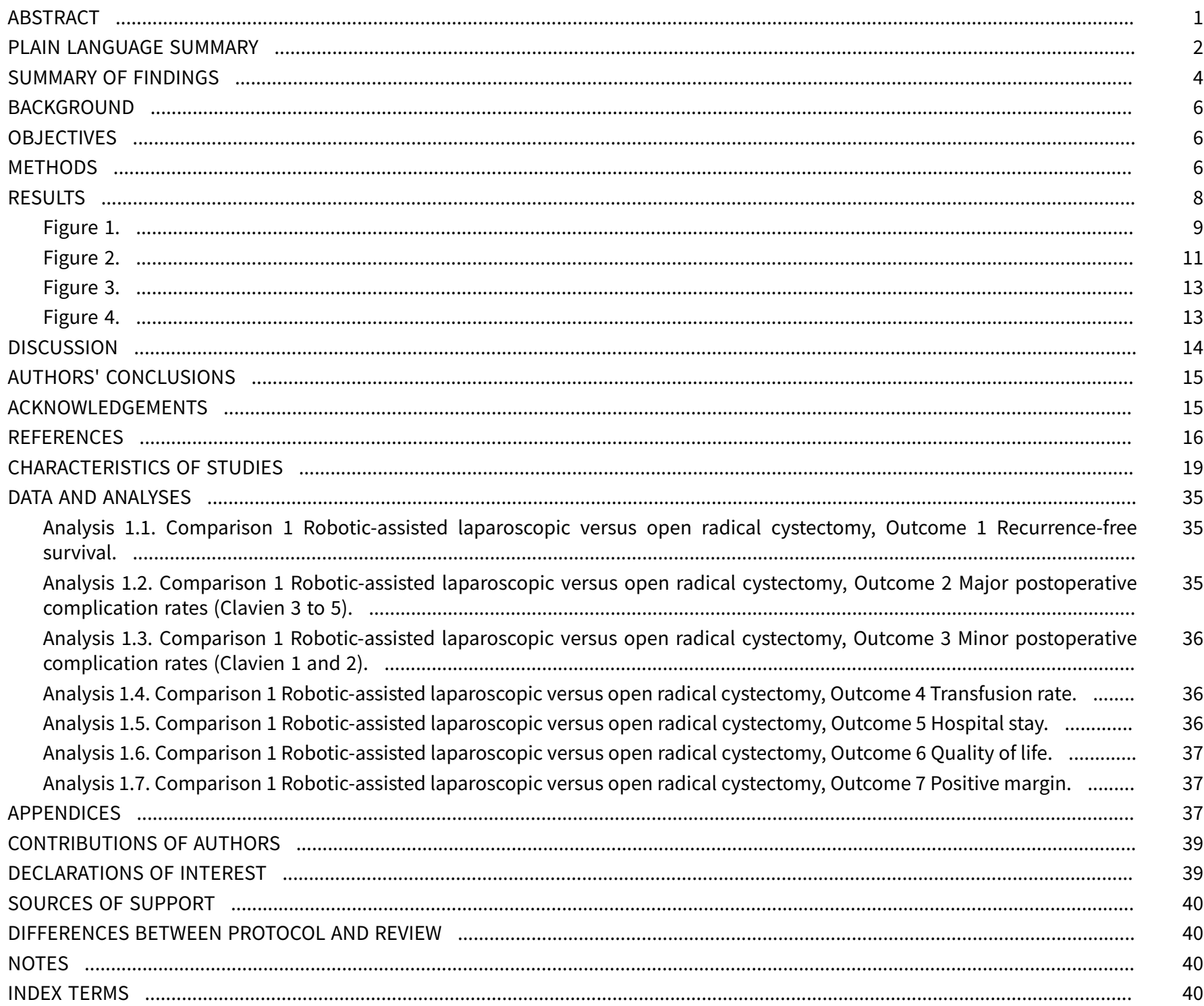


[Intervention Review]

\section{Robotic versus open radical cystectomy for bladder cancer in adults}

Bhavan Prasad Rai1 ${ }^{1}$, Jasper Bondad², Nikhil Vasdev³, Jim Adshead³, Tim Lane 3 , Kamran Ahmed4, Mohammed S Khan 4 , Prokar Dasgupta4, Khurshid Guru5, Piotr L Chlosta6, Omar M Aboumarzouk?

1Department of Urology, Freeman Hospital, The Newcastle upon Tyne Hospitals NHS Foundation Trust, Newcastle Upon Tyne, UK. 2Department of Urology, Southend Hospital, Westcliff-on-Sea, UK. ${ }^{3}$ Department of Urology, Lister Hospital, Stevenage, UK. ${ }^{4}$ MRC Centre for Transplantation, Division of Transplantation Immunology and Mucosal Biology, School of Medicine, King's College London, London, UK. ${ }^{5}$ Department of Urology, Roswell Park Cancer Institute, Buffalo, New York, USA. ${ }^{6}$ Department of Urology, Jagiellonian University, Collegium Medicum, Krakow, Poland. ${ }^{7}$ Department of Urology, NHS Greater Glasgow and Clyde, Glasgow, UK

Contact: Omar M Aboumarzouk, Department of Urology, NHS Greater Glasgow and Clyde, Queen Elizabeth University Hospital, Glasgow, Scotland, UK. aboumarzouk@gmail.com,drbigo31262@gmail.com.

Editorial group: Cochrane Urology Group.

Publication status and date: New, published in Issue 4, 2019.

Citation: Rai BP, Bondad J, Vasdev N, Adshead J, Lane T, Ahmed K, Khan MS, Dasgupta P, Guru K, Chlosta PL, Aboumarzouk OM. Robotic versus open radical cystectomy for bladder cancer in adults. Cochrane Database of Systematic Reviews 2019, Issue 4. Art. No.: CD011903. DOI: 10.1002/14651858.CD011903.pub2.

Copyright @ 2019 The Cochrane Collaboration. Published by John Wiley \& Sons, Ltd.

\section{A B S T R A C T}

\section{Background}

It has been suggested that in comparison with open radical cystectomy, robotic-assisted radical cystectomy results in less blood loss, shorter convalescence, and fewer complications with equivalent short-term oncological and functional outcomes; however, uncertainty remains as to the magnitude of these benefits.

\section{Objectives}

To assess the effects of robotic-assisted radical cystectomy versus open radical cystectomy in adults with bladder cancer.

\section{Search methods}

Review authors conducted a comprehensive search with no restrictions on language of publication or publication status for studies comparing open radical cystectomy and robotic-assisted radical cystectomy. The date of the last search was 1 July 2018 for the Cochrane Central Register of Controlled Trials, MEDLINE (1999 to July 2018), PubMed Embase (1999 to July 2018), Web of Science (1999 to July 2018), Cancer Research UK (www.cancerresearchuk.org/), and the Institute of Cancer Research (www.icr.ac.uk/). We searched the following trials registers: ClinicalTrials.gov (clinicaltrials.gov/), BioMed Central International Standard Randomized Controlled Trials Number (ISRCTN) Registry (www.isrctn.com), and the World Health Organization International Clinical Trials Registry Platform.

\section{Selection criteria}

We searched for randomised controlled trials that compared robotic-assisted radical cystectomy (RARC) with open radical cystectomy (ORC).

\section{Data collection and analysis}

This study was based on a published protocol. Primary outcomes of the review were recurrence-free survival and major postoperative complications (class III to V). Secondary outcomes were minor postoperative complications (class I and II), transfusion requirement, length of hospital stay (days), quality of life, and positive margins (\%). Three review authors independently assessed relevant titles and abstracts of records identified by the literature search to determine which studies should be assessed further. Two review authors assessed risk of bias using the Cochrane risk of bias tool and rated the quality of evidence according to GRADE. We used Review Manager 5 to analyse the data. 


\section{Main results}

We included in the review five randomised controlled trials comprising a total of 541 participants. Total numbers of participants included in the ORC and RARC cohorts were 270 and 271 , respectively.

\section{Primary outomes}

Time-to-recurrence: Robotic cystectomy and open cystectomy may result in a similar time to recurrence (hazard ratio (HR) 1.05 , 95\% confidence interval ( $\mathrm{Cl}) 0.77$ to 1.43); 2 trials; low-certainty evidence). In absolute terms at 5 years of follow-up, this corresponds to 16 more recurrences per 1000 participants ( $95 \% \mathrm{Cl} 79$ fewer to 123 more) with 431 recurrences per 1000 participants for ORC. We downgraded the certainty of evidence for study limitations and imprecision.

Major complications (Clavien grades 3 to 5): Robotic cystectomy and open cystectomy may result in similar rates of major complications (risk ratio (RR) $1.06,95 \% \mathrm{Cl} 0.76$ to 1.48 ); 5 trials; low-certainty evidence). This corresponds to 11 more major complications per 1000 participants ( $95 \% \mathrm{Cl} 44$ fewer to 89 more). We downgraded the certainty of evidence for study limitations and imprecision.

\section{Secondary outcomes}

Minor complications (Clavien grades 1 and 2): We are very uncertain whether robotic cystectomy may reduce minor complications (very low-certainty evidence). We downgraded the certainty of evidence for study limitations and for very serious imprecision.

Transfusion rate: Robotic cystectomy probably results in substantially fewer transfusions than open cystectomy $(\mathrm{RR} 0.58,95 \% \mathrm{Cl} 0.43$ to $0.80 ; 2$ trials; moderate-certainty evidence). This corresponds to 193 fewer transfusions per 1000 participants ( $95 \% \mathrm{Cl} 262$ fewer to 92 fewer) based on 460 transfusion per 1000 participants for ORC. We downgraded the certainty of evidence for study limitations.

Hospital stay: Robotic cystectomy may result in a slightly shorter hospital stay than open cystectomy (mean difference (MD) $-0.67,95 \% \mathrm{Cl}$ -1.22 to -0.12 ); 5 trials; low-certainty evidence). We downgraded the certainty of evidence for study limitations and imprecision.

Quality of life: Robotic cystectomy and open cystectomy may result in a similar quality of life (standard mean difference (SMD) $0.08,95 \% \mathrm{Cl}$ 0.32 lower to 0.16 higher; 3 trials; low-certainty evidence). We downgraded the certainty of evidence for study limitations and imprecision.

Positive margin rates: Robotic cystectomy and open cystectomy may result in similar positive margin rates ( $\mathrm{RR} 1.16,95 \% \mathrm{Cl} 0.56$ to 2.40 ; 5 trials; low-certainty evidence). This corresponds to 8 more $(95 \% \mathrm{Cl} 21$ fewer to 67 more) positive margins per 1000 participants based on 48 positive margins per 1000 participants for ORC. We downgraded the certainty of evidence for study limitations and imprecision.

\section{Authors' conclusions}

Robotic cystectomy and open cystectomy may have similar outcomes with regard to time to recurrence, rates of major complications, quality of life, and positive margin rates (all low-certainty evidence). We are very uncertain whether the robotic approach reduces rates of minor complications (very low-certainty evidence), although it probably reduces the risk of blood transfusions substantially (moderatecertainty evidence) and may reduce hospital stay slightly (low-certainty evidence). We were unable to conduct any of the preplanned subgroup analyses to assess the impact of patient age, pathological stage, body habitus, or surgeon expertise on outcomes. This review did not address issues of cost-effectiveness.

\section{PLAIN LANGUAGE SUMMARY}

\section{Robotic versus open radical cystectomy for bladder cancer in adults}

\section{Review question}

For patients with bladder cancer that involves the deep muscle wall, does use of a robotic device lead to better or worse outcomes than open surgery?

\section{Background}

Patients with bladder cancer that involves the deep muscle wall are best treated by an operation that removes the entire bladder and creates an artificial bladder or channel from the bowel to allow urine to drain to the outside world. This has been done traditionally through open surgery using one large incision. Recently, this operation has been performed with robotic assistance using several small incisions. It is uncertain which approach is better.

\section{Study characteristics}

We performed a comprehensive literature search until 1 July 2018. We found five trials comparing robotic assisted versus open surgery. The total number of participants in these trials was 541. Four studies were conducted in the USA and one in the UK.

\section{Key results}


There may be little to no difference in the time to recurrence, the rate of major complications or minor complications, quality of life, and rates of positive margins (signalling that cancer may have been left behind). Robotic surgery probably results in fewer blood transfusions and may lead to a slightly shorter hospital stay when compared with open surgery.

\section{Certainty of evidence}

Reviewers rated the certainty of evidence as low for most outcomes, except for minor complications (very low) and transfusions (moderate). This means that the true results for these outcomes could be quite different. 
SUMMARY OF FINDINGS

Summary of findings for the main comparison. Robotic-assisted laparoscopic vs open radical cystectomy for bladder cancer in adults

Robotic-assisted laparoscopic vs open radical cystectomy for bladder cancer in adults

Patient or population: bladder cancer in adults

Setting: tertiary care centres in the United States and the United Kingdom

Intervention: robotic-assisted laparoscopic cystectomy

Comparison: open radical cystectomy

\begin{tabular}{|c|c|c|c|c|c|}
\hline \multirow[t]{2}{*}{ Outcomes } & \multirow{2}{*}{$\begin{array}{l}\text { No. of partici- } \\
\text { pants } \\
\text { (studies) } \\
\text { Follow-up }\end{array}$} & \multirow{2}{*}{$\begin{array}{l}\text { Certainty of the } \\
\text { evidence } \\
\text { (GRADE) }\end{array}$} & \multirow{2}{*}{$\begin{array}{l}\text { Relative effect } \\
(95 \% \mathrm{CI})\end{array}$} & \multicolumn{2}{|c|}{ Anticipated absolute effects* $(95 \% \mathrm{CI})$} \\
\hline & & & & $\begin{array}{l}\text { Risk with open radi- } \\
\text { cal cystectomy }\end{array}$ & $\begin{array}{l}\text { Risk difference with robot- } \\
\text { ic-assisted laparoscopic cys- } \\
\text { tectomy }\end{array}$ \\
\hline \multirow{2}{*}{$\begin{array}{l}\text { Time to recurrence (here: recurrence rate at } 5 \\
\text { years) }{ }^{1} \\
\text { assessed with clinical examination and imag- } \\
\text { ing }\end{array}$} & \multirow[t]{2}{*}{$\begin{array}{l}277 \\
(2 \mathrm{RCTS})\end{array}$} & \multirow[t]{2}{*}{$\begin{array}{l}\oplus \oplus \ominus \ominus \\
\text { LOWa,b }\end{array}$} & \multirow[t]{2}{*}{$\begin{array}{l}\text { HR } 1.05 \\
\text { (0.77 to } 1.43)\end{array}$} & \multicolumn{2}{|l|}{ Study population } \\
\hline & & & & 431 per 1000 & $\begin{array}{l}16 \text { more per } 1000 \\
\text { ( } 79 \text { fewer to } 123 \text { more) }\end{array}$ \\
\hline \multirow{2}{*}{$\begin{array}{l}\text { Major postoperative complications } \\
\text { assessed with Clavien-Dindo system (rated } \\
\text { grade } 3 \text { to } 5 \text { ) }\end{array}$} & \multirow{2}{*}{$\begin{array}{l}541 \\
\text { (5 RCTs) }\end{array}$} & \multirow{2}{*}{$\begin{array}{l}\oplus \oplus \odot \ominus \\
\text { LOWb,c }\end{array}$} & \multirow{2}{*}{$\begin{array}{l}\text { RR } 1.06 \\
\text { (0.76 to } 1.48)\end{array}$} & \multicolumn{2}{|l|}{ Study population } \\
\hline & & & & 185 per 1000 & $\begin{array}{l}11 \text { more per } 1000 \\
\text { (44 fewer to } 89 \text { more) }\end{array}$ \\
\hline \multirow{2}{*}{$\begin{array}{l}\text { Minor postoperative complications assessed } \\
\text { with Clavien-Dindo system (rated grade } 1 \text { or } \\
\text { 2) }\end{array}$} & \multirow{2}{*}{$\begin{array}{l}423 \\
(4 \mathrm{RCTs})\end{array}$} & \multirow{2}{*}{$\begin{array}{l}\oplus \ominus \ominus \ominus \\
\text { VERY LOWc,d }\end{array}$} & \multirow{2}{*}{$\begin{array}{l}\text { RR } 0.82 \\
\text { (0.58 to } 1.17)\end{array}$} & \multicolumn{2}{|l|}{ Study population } \\
\hline & & & & 443 per 1000 & $\begin{array}{l}80 \text { fewer per } 1000 \\
\text { (186 fewer to } 75 \text { more) }\end{array}$ \\
\hline \multirow{2}{*}{$\begin{array}{l}\text { Transfusion rate assessed with transfused } \\
\text { units of packed red blood cells }\end{array}$} & \multirow{2}{*}{$\begin{array}{l}326 \\
(2 \mathrm{RCTs})\end{array}$} & \multirow{2}{*}{$\begin{array}{l}\oplus \oplus \oplus \ominus \\
\text { MODERATEC }\end{array}$} & \multirow{2}{*}{$\begin{array}{l}\text { RR } 0.58 \\
(0.43 \text { to } 0.80)\end{array}$} & \multicolumn{2}{|l|}{ Study population } \\
\hline & & & & 460 per 1000 & $\begin{array}{l}193 \text { fewer per } 1000 \\
\text { ( } 262 \text { fewer to } 92 \text { fewer) }\end{array}$ \\
\hline Hospital stay assessed in days & $\begin{array}{l}541 \\
(5 \mathrm{RCTs})\end{array}$ & $\begin{array}{l}\oplus \oplus \ominus \ominus \\
\text { LOWb,c }\end{array}$ & - & $\begin{array}{l}\text { Mean hospital stay } \\
\text { ranged from } 5.1 \text { to } \\
11.9 \text { days }\end{array}$ & $\begin{array}{l}\text { MD } 0.67 \text { days lower } \\
\text { (1.22 lower to } 0.12 \text { lower) }\end{array}$ \\
\hline $\begin{array}{l}\text { Quality of life (higher scores indicate better } \\
\text { quality of life) }\end{array}$ & $\begin{array}{l}270 \\
\text { (3 RCTs) }\end{array}$ & $\begin{array}{l}\oplus \oplus \ominus \ominus \\
\text { LOWc,e }\end{array}$ & - & $\begin{array}{l}\text { Mean quality of life } \\
\text { (higher scores indi- }\end{array}$ & $\begin{array}{l}\text { SMD } 0.08 \text { SD lower } \\
\text { ( } 0.32 \text { lower to } 0.16 \text { higher) }\end{array}$ \\
\hline
\end{tabular}


${ }^{*}$ The risk in the intervention group (and its $95 \%$ confidence interval) is based on the assumed risk in the comparison group and the relative effect of the intervention (and its $95 \% \mathrm{Cl}$ ).

Cl: confidence interval; HR: hazard ratio; MD: mean difference; RCT: randomised controlled trial; RR: risk ratio; SMD: standardised mean difference.

\section{GRADE Working Group grades of evidence.}

High certainty: We are very confident that the true effect lies close to that of the estimate of the effect.

Moderate certainty: We are moderately confident in the effect estimate: the true effect is likely to be close to the estimate of the effect, but there is a possibility that it is substantially different.

Low certainty: Our confidence in the effect estimate is limited: the true effect may be substantially different from the estimate of the effect.

Very low certainty: We have very little confidence in the effect estimate: the true effect is likely to be substantially different from the estimate of effect.

${ }^{1}$ The control event rate at 5 years was based on an overall recurrence rate of 25/58 (43.1\%) in the ORC arm reported in Bochner 2015

aDowngraded by one level for study limitations; risk of performance, detection, and attrition bias.

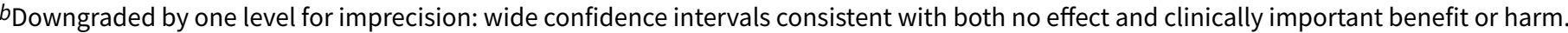

cDowngraded by one level for study limitations; risk of performance and detection bias.

$d$ Downgraded by two levels for very serious imprecision: wide confidence interval consistent with small benefit, no effect, and small harm.

eDowngraded by one level for imprecision: wide confidence intervals consistent with both no effect and clinically important reduction in quality of life, assuming SMD of 0.2 . 


\section{B A C K G R O U N D}

\section{Description of the condition}

Over 400,000 new cases of bladder cancer are diagnosed annually, accounting for $3 \%$ of all cancers (Ferlay 2013; Ferlay 2015; Ploeg 2009). Radical cystectomy (RC) with pelvic lymph node dissection (PLND) and urinary diversion is the gold standard surgical treatment for muscle-invasive bladder cancer (MIBC) (Hayn 2010; Jonsson 2011; Lee 2011; Redorta 2010; Smith 2011; Witjes 2014). Other indications for RC include high-risk non-muscle-invasive bladder cancer (NMIBC) and recurrent multifocal superficial disease (Hayn 2010; Jonsson 2011; Lee 2011; Redorta 2010; Smith 2011; Witjes 2014). The procedure has traditionally been performed using an open approach. Morbidity with open radical cystectomy (ORC) is high. In a retrospective review of a prospectively maintained database of 1142 patients who underwent ORC/ urinary diversion by high-volume fellowship-trained urological oncologists, the reported 90-day overall complication rate and the 30 -day mortality rate were $64 \%$ and $1.5 \%$, respectively (Shabsigh 2009).

\section{Description of the intervention}

A significant interest in minimally invasive surgery (MIS) has arisen in the last two decades in an attempt to reduce morbidity, expedite recovery, and decrease hospital stay (Hu 2009; Schwenk 2005; Wright 2013). MIS approaches, both conventional laparoscopy and robotic-assisted approaches, have replaced a significant number of open surgical techniques (Hu 2009; Schwenk 2005; Wright 2013). The uptake of conventional laparoscopic radical cystectomy has been impeded by technical challenges associated with the procedure, in particular the reconstructive aspects of the procedure (Aboumarzouk 2012; Aboumarzouk 2013; Castillo 2006; Castillo 2009; Cathelineau 2005; Haber 2008; Hosseini 2011; Huang 2008; Huang 2010; Jonsson 2011; Khan 2011; Sighinolfi 2007; Smith 2011). Robotic-assisted radical cystectomy (RARC)-which offers such advantages as increased manoeuvrability, superior magnification, enhanced EndoWrist ${ }^{\circledR}$ dexterity, and tremor elimination-has been suggested as an alternative to overcome issues associated with the conventional laparoscopic approach (Ishii 2014).

\section{How the intervention might work}

Adoption of the robotic approach has been swift in contemporary urological practice, with widespread application of robotic-assisted radical prostatectomy and robotic-assisted partial nephrectomy in Europe and the USA leading to favourable perioperative outcomes in comparison with open and laparoscopic counterparts (Novara 2012). Three systematic reviews of randomised and nonrandomised controlled trials suggested shorter operative time and less blood loss for ORC when compared with RARC (Ishii 2014; Novara 2015; Tang 2014). These reviews also demonstrated reduced Clavien grade 3 complications for RARC. Two comparative studies have suggested similar survival outcomes between ORC and RARC (Khan 2012; Nepple 2013).

\section{Why it is important to do this review}

Although over 2000 procedures have been reported to the International Robotic Cystectomy Consortium from 37 centres worldwide, well-conducted studies comparing RARCs to ORCs are lacking (Raza 2015). Randomised controlled trials are necessary to establish how RARC compares to ORC. We performed a systematic review to summarise and critically appraise the body of evidence comparing these two approaches to inform clinical decisionmaking as well as health policy.

\section{O B JECTIVES}

To assess the effects of robotic-assisted radical cystectomy versus open radical cystectomy in adults with bladder cancer.

\section{METHODS}

\section{Criteria for considering studies for this review \\ Types of studies}

We included all randomised controlled trials (RCTs) and quasiRCTs of individual participants comparing ORC and RARC. We did not include cluster-randomised trials. We considered all studies regardless of their publication status and language of publication.

\section{Types of participants}

We included adult participants with a diagnosis of bladder malignancy who were undergoing radical cystectomy as part of their treatment for pathologically proven MIBC or highgrade NMIBC (T1-4/carcinoma in situ (CIS), NOM0). We included participants irrespective of histological bladder cancer type (i.e. we included those with urothelial cell carcinoma, squamous cell carcinoma, or adenocarcinoma). We included participants receiving neoadjuvant or adjuvant chemotherapy. We excluded studies of participants with prior radiotherapy in which cystectomy was performed as a salvage procedure.

\section{Types of interventions}

We investigated the following comparison of experimental intervention versus comparator intervention. We included trials independent of the urinary diversion method employed. We analysed data by intention-to-treat analysis.

\section{Experimental intervention}

Robotic-assisted radical cystectomy.

\section{Comparator intervention}

Open radical cystectomy.

\section{Types of outcome measures}

\section{Primary outcomes}

- Time to recurrence

- Major postoperative complications (class III to V) (Dindo 2004)

\section{Secondary outcomes}

- Minor postoperative complications (class I and II) (Dindo 2004)

- Transfusion requirement

- Length of hospital stay (days)

- Quality of life as evaluated via validated participant-reported questionnaire scores or domains reflecting overall or global health of the participant

- Positive margins (\%) 


\section{Search methods for identification of studies}

\section{Electronic searches}

We performed a comprehensive search with no restrictions on language of publication nor publication status. We searched the following electronic databases (date of last search was 1 July 2018):

- Cochrane Central Register of Controlled Trials (CENTRAL; latest issue) in the Cochrane library via Wiley

- MEDLINE (1999 to July 2018); PubMed search. We used these terms and medical subject heading (MeSH) phrases: (cystectomy [MeSH terms] AND robotic AND open) AND "surgery" [MeSH subheading]

- EMBASE (1999 to July 2018); Ovid search using the terms cystectomy, open, and robotic

- Web of Science (1999 to July 2018)

- Cancer Research UK (www.cancerresearchuk.org/)

- Institute of Cancer Research (www.icr.ac.uk/)

We searched the following trials registers:

- ClinicalTrials.gov (clinicaltrials.gov/)

- BioMed Central ISRCTN registry (www.isrctn.com)

- World Health Organization International Clinical Trials Registry Platform (WHO ICTRP; www.who.int/ictrp/en/)

See Appendix 1 for search terms used in strategies for this review. We limited back-searching from 1999 onward because the earliest da Vinci robotic-assisted device was not introduced until 1999 (Ballantyne 2003).

\section{Searching other resources}

We further evaluated the reference lists of included studies and of relevant review articles identified by the search. To identify unpublished studies, we searched the online conference proceedings of annual meetings of the American Urological Association (www.auanet.org) and the European Association of Urology (http://uroweb.org) from 2012 to July 2018.

\section{Data collection and analysis}

\section{Selection of studies}

Three review authors (BR, OMA, JB) independently assessed relevant titles and abstracts of records identified by the literature search to determine which studies should be assessed further Three review authors (BR, OMA, JB) investigated all potentially relevant records as full text, mapped records to unique studies, and classified studies as included studies, excluded studies, studies awaiting classification, or ongoing studies, in accordance with the criteria for each provided in the Cochrane Handbook for Systematic Reviews of Interventions (Higgins 2011). We resolved any disagreement by discussion and consensus or by recourse to a fourth review author (KG). We adapted a PRISMA flow diagram to demonstrate the process of study selection (Liberati 2009).

\section{Data extraction and management}

For studies that fulfil inclusion criteria, three review authors (BR, $\mathrm{OMA}, \mathrm{JB}$ ) independently extracted the following information, which is provided in the Characteristics of included studies tables:

\section{- Study design (e.g. parallel-group randomised trial)}

- Study dates (if dates were not available, this was reported)

- Study settings and country

- Participant inclusion and exclusion criteria

- Participant details and baseline demographics, such as age and sex

- Numbers of participants by study and by study arm

- Details of relevant experimental and comparator interventions and conversion rates from robotic to open

- Definitions of relevant outcomes and methods and timing of outcome measurement, as well as any relevant subgroups

- Study funding sources

- Declarations of interest by primary investigators

For dichotomous outcomes, we attempted to obtain numbers of events and totals for populations on a $2 \times 2$ table, as well as summary statistics with corresponding measures of variance. For continuous outcomes, we attempted to obtain means and standard deviations or data necessary to calculate this information. For timeto-event outcomes, we attempted to obtain hazard ratios (HRs) with corresponding measures of variance or data necessary to calculate this information.

We resolved all disagreements by consensus.

\section{Dealing with duplicate and companion publications}

In the event of duplicate publications, companion documents, or multiple reports of a primary study, we maximised the yield of information by mapping all publications to unique studies and collating all available data. We used the most complete data set aggregated across all known publications. In case of doubt, we gave priority to the publication reporting the longest follow-up associated with our primary or secondary outcomes.

\section{Assessment of risk of bias in included studies}

Two review authors (BR, OMA) independently assessed the risk of bias of each included study and resolved all disagreements by consensus.

We assessed risk of bias using Cochrane's 'Risk of bias' assessment tool for the following domains (Higgins 2011):

- Random sequence generation (selection bias)

- Allocation concealment (selection bias)

- Blinding of participants and personnel (performance bias)

- Blinding of outcome assessment (detection bias)

- Incomplete outcome data (attrition bias)

- Selective reporting (reporting bias)

- Other sources of bias

For detection bias, we evaluated the risk of bias separately for each outcome. We regarded outcomes such as transfusion requirement and hospital stay as objective, and, if reported, we judged these studies as low risk. If studies did not report these outcomes, we judged them as unclear risk.

For attrition bias, we evaluated risk of bias separately for quality of life. We combined the outcomes major and minor postoperative complications, hospital stay, transfusion requirement, and positive margin rates into a single group for attrition bias. 


\section{Measures of treatment effect}

We used Review Manager 5 (RevMan 5) (RevMan) to analyse the data. We expressed dichotomous outcomes as risk ratios (RRs) with 95\% confidence intervals (Cls). For time-to-event outcomes, we calculated the hazard ratio with $95 \% \mathrm{Cl}$. We expressed continuous data as mean differences (MDs) or standardised mean differences (SMDs) (if the same outcome was evaluated by different tools) with $95 \% \mathrm{Cls}$

\section{Unit of analysis issues}

Parallel-group designs were to be analysed. The unit of analysis was the individual participant. In the event we identified trials with more than two intervention groups for inclusion in the review, we handled these in accordance with guidance provided in the Cochrane Handbook for Systematic Reviews of Interventions (Higgins 2011).

\section{Dealing with missing data}

When data were missing, we contacted corresponding authors of the trials (Bochner 2015; Nix 2010; Parekh 2013; Parekh 2018). We had received no response from the corresponding authors of individual trials at the time of submission of this review. We imputed missing standard deviations in accordance with guidance provided in the Cochrane Handbook for Systematic Reviews of Interventions (Higgins 2011). We imputed means and standard deviations from median and range in accordance with guidance provided in Hozo 2005.

\section{Assessment of heterogeneity}

In the event of excessive heterogeneity unexplained by subgroup analyses, we did not report outcome results as the pooled effect estimate in a meta-analysis.

We identified heterogeneity by using a $\mathrm{Chi}^{2}$ test on $\mathrm{N}-1$ degrees of freedom, with an alpha of 0.05 for statistical significance, and using the $I^{2}$ statistic (Higgins 2003). We interpreted the $I^{2}$ statistic as follows:

- $0 \%$ to $40 \%$ : may not be important

- $30 \%$ to $60 \%$ : may indicate moderate heterogeneity

- $50 \%$ to $90 \%$ : may indicate substantial heterogeneity

- $75 \%$ to $100 \%$ : indicates considerable heterogeneity

\section{Assessment of reporting biases}

We planned to obtain study protocols to evaluate studies for reporting bias. We did not formally perform funnel plot analysis, as the review included only five trials.

\section{Data synthesis}

We summarised data using a random-effects model. We interpreted random-effects meta-analyses with due consideration of the whole distribution of effects. In addition, we performed statistical analyses according to the statistical guidelines provided in the Cochrane Handbook for Systematic Reviews of Interventions (Higgins 2011). For dichotomous outcomes, we used the Mantel-Haenszel method; for continuous outcomes, we used the inverse variance method; and for time-to-event outcomes, we used the generic inverse variance method. We used RevMan software to perform analyses.

\section{GRADE and 'Summary of findings' table}

We presented the overall quality of evidence for each outcome according to the GRADE approach, which takes into account five criteria related not only to internal validity (risk of bias, inconsistency, imprecision, publication bias), but also to external validity, such as directness of results (Guyatt 2008). Two review authors (BR, OMA) independently rated the quality of evidence for each outcome as 'high', 'moderate', 'low', or 'very low', using GRADEpro GDT. We resolved any discrepancies by consensus. We presented a summary of evidence for the main outcomes in a 'Summary of findings' table, which provides key information about the best estimate of the magnitude of effect in relative terms and absolute differences for each relevant comparison of alternative management strategies; numbers of participants and studies addressing each important outcome; and the rating of overall confidence in effect estimates for each outcome (Guyatt 2011).

\section{Main outcomes for 'Summary of findings' table}

We have presented a 'Summary of findings' table to report the following outcomes listed according to priority:

- Time to recurrence

- Major postoperative complications (class III to V) (Dindo 2004)

- Minor postoperative complications (class I and II) (Dindo 2004)

- Length of hospital stay (days)

- Quality of life

- Positive margins (\%)

\section{Subgroup analysis and investigation of heterogeneity}

We attempted to perform subgroup analyses to explore possible sources of heterogeneity. We considered the following subgroups:

- Participant age (younger than 60 years vs 60 years of age and older)

- Participant body mass index $\left(<30 \mathrm{~kg} / \mathrm{m}^{2} \mathrm{vs} \geq 30 \mathrm{~kg} / \mathrm{m}^{2}\right)$

- Pathological stage ( $\leq$ pT2 disease vs pT3 disease)

- Surgeon's level of experience (less than expert vs expert, as defined by trial authors)

We planned to test for subgroup differences using RevMan 5 to compare subgroup analyses if we found sufficient studies (RevMan). We could not do this with the information provided in the included studies.

\section{RES U L T S}

\section{Description of studies}

We identified 332 references through electronic searches of the different databases.

We retrieved a total of 32 references for further detailed assessment. We excluded 26 references for the reasons listed in the Characteristics of excluded studies table. We found that seven references on five randomised controlled trials (RCTs) fulfilled the review inclusion criteria (see Characteristics of included studies). Two trials published outcomes in two separate publications (Bochner 2015; Parekh 2013). We have presented the reference flow in Figure 1. 
Figure 1. Study flow diagram.

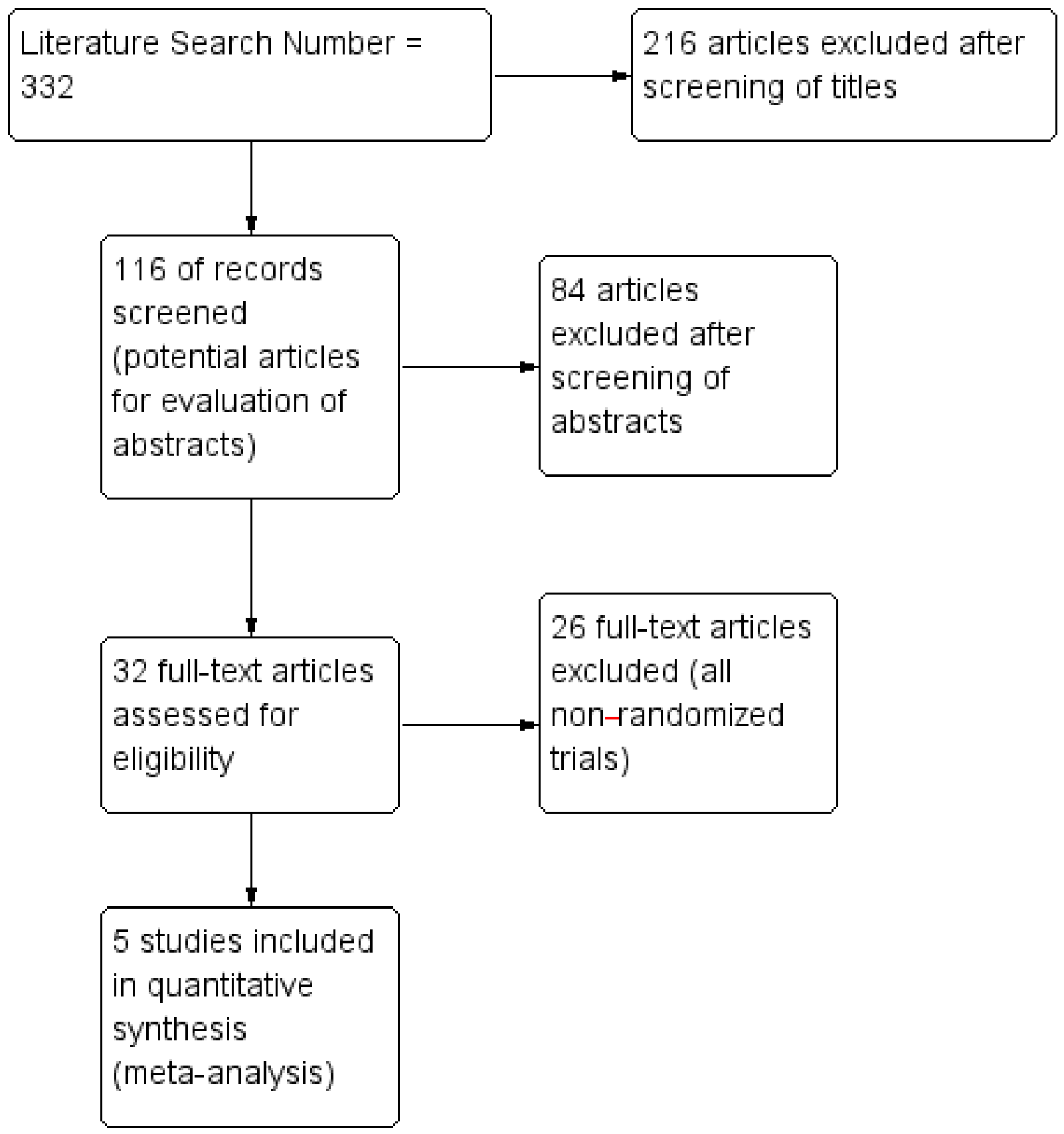

\section{Included studies}

\section{Study design and setting}

Five trials were published between 2010 and 2018:

- Nix 2010 reported the first trial of RARC versus ORC. Researchers conducted this study at the University of North Carolina in the USA and randomised 21 participants to an open approach and 20 to a robotic-assisted laparoscopic approach. The study had a noninferiority design, and its primary outcome was lymph node yield.

- The RAZOR trial (a prospective, multicentre, randomised trial of open vs robotic radical cystectomy) was the largest and most recently published trial (Parekh 2018). It was conducted at 15 academic centres in the USA and randomised 159 and 153 participants to RARC and ORC cohorts, respectively (Parekh 2018). After exclusions, 150 participants were included in the RARC cohort and 152 participants in the ORC cohort, in the per-protocol analysis set (Parekh 2018). The study used a noninferiority design and included a primary outcome of progression-free survival at two years.

- Parekh 2013 reported the results of a preceding pilot trial leading up to the RAZOR trial that was conducted at the University of Texas at San Antonio in the USA. Study authors randomised 20 participants each to RARC and ORC and reported oncological outcomes and quality of life outcomes - in two

Robotic versus open radical cystectomy for bladder cancer in adults (Review)

Copyright (c) 2019 The Cochrane Collaboration. Published by John Wiley \& Sons, Ltd. 
separate publications (Parekh 2013). This study had no specific primary endpoint aside from establishing randomisation.

- Bochner 2015 reported the results of a single-institution, randomised trial conducted at Memorial Sloan Kettering Cancer Center in the USA. Investigators randomised 60 and 58 participants to RARC and ORC cohorts, respectively. The study was described as an expertise-based trial. Study authors reported oncological outcomes in a second publication.

- Khan 2016 reported the results of a single-institution, threearmed, randomised trial conducted at Guy's Hospital, in London, United Kingdom, that randomised 20 participants each to RARC, ORC, and (pure) laparoscopic cystectomy. This study was described as an expertise-based trial.

\section{Participants}

The total numbers of participants included in the ORC and RARC cohorts were 270 and 271, respectively. Most participants in both the ORC $(221 ; 82 \%)$ and RARC $(226 ; 83.4 \%)$ groups were men. Three studies reported demographic data using the median (Bochner 2015; Parekh 2013; Parekh 2018) and two using the mean (Khan 2016; Nix 2010). The mean age of participants in the ORC cohort ranged between 66.6 years and 69.2 years. The mean age of participants in the RARC cohort ranged between 67.4 years and 68.6 years. The median age of participants in the ORC cohort ranged between 64.5 years and 65 years. The median age of participants in the RARC cohort ranged between 66 years and 69.5 years. The mean body mass index (BMI) (in $\mathrm{kg} / \mathrm{m}^{2}$ ) of participants in the ORC cohort ranged between 27.4 and 28.4. The mean BMI $\left(\mathrm{kg} / \mathrm{m}^{2}\right)$ of participants in the RARC cohort ranged were similar at 27.5. The median BMI $\left(\mathrm{kg} / \mathrm{m}^{2}\right)$ of participants in the ORC cohort ranged between 24.9 and 31.7 , and the median BMI $\left(\mathrm{kg} / \mathrm{m}^{2}\right)$ of participants in the RARC cohort ranged between 25 and 30.8 .

\section{Interventions and comparators}

All five studies compared ORC to RARC (Bochner 2015; Khan 2016; Nix 2010; Parekh 2013; Parekh 2018); one trial included an arm of laparoscopic radical cystectomy (Khan 2016). Four studies performed urinary diversion extracorporeally (Bochner 2015; Khan 2016; Nix 2010; Parekh 2018). One study performed urinary diversion at the discretion of the surgeon and did not explicitly report the type (Parekh 2013). In the ORC cohort, urinary diversion was ileal conduit, neobladder, and continent cutaneous type in 194 (72\%), 73 (27\%), and $3(1 \%)$ participants, respectively. In the RARC cohort, urinary diversion was ileal conduit, neobladder, and continent cutaneous type in $191(70.6 \%), 79(29 \%)$, and $1(0.4 \%)$ participant, respectively. All five trials performed a pelvic lymph node dissection (Bochner 2015; Khan 2016; Nix 2010; Parekh 2013; Parekh 2018). We have summarised the inclusion criteria for each study in the Characteristics of included studies table.

\section{Outcomes}

Bochner 2015 reported on patient-reported outcomes (PROs) of quality of life (QoL) using the validated European Organisation for Research and Treatment of Cancer (EORTC) Quality of Life Questionnaire Core 30 (QLQ-C30) survey. Khan 2016 evaluated QoL using the validated Functional Assessment of Cancer Therapy Bladder (FACT-Bl) scale v4 questionnaire. Parekh 2013 and Parekh 2018 evaluated QoL using the validated Functional Assessment of Cancer Therapy -Vanderbilt Cystectomy Index (FACT-VCI) questionnaire.

\section{Funding}

Parekh 2018 was funded by the National Institutes of Health National Cancer Institute.

Bochner 2015 was supported by the Sidney Kimmel Center for Prostate and Urologic Cancers at Memorial Sloan Kettering Cancer Center, Pin Down Bladder Cancer, and the Michael and Zena Wienerfor Therapeutics Program in Bladder Cancer. Study sponsors were involved in the design and conduct of the study; in collection, analysis, management, and interpretation of the data; and in preparation, review, and approval of the manuscript.

Khan 2016 was supported by the National Institute for Health Research (NIHR) Biomedical Research Centre based at Guy's and St. Thomas' NHS Foundation Trust and King's College London. Study authors acknowledge support from the NIHR Biomedical Research Centre, the Medical Research Council Centre for Transplantation, King's Health Partners, Guy's and St. Thomas' Charity, the School of Surgery, the London Deanery, the Royal College of Surgeons of England, Intuitive Surgical, the Urology Foundation, Olympus, EUFP7, ProstateCancer UK, the Technology Strategy Board, and the Vattikuti Foundation.

The remaining two studies did not report funding (Nix 2010; Parekh 2013).

\section{Excluded studies}

We excluded 26 of these publications. All of these studies were nonrandomised comparative studies comparing ORC and RARC (Excluded studies). We have documented further details of individual studies in the Characteristics of excluded studies table.

\section{Risk of bias in included studies}

We have summarised the methodology and risk of bias of individual trials in the Characteristics of included studies table.

We have summarised the risk of bias for individual trials in Figure 2. 
Figure 2. Risk of bias summary: review authors' judgements about each risk of bias item for each included study.

\begin{tabular}{|c|c|c|c|c|c|c|c|c|c|c|c|c|c|c|}
\hline & 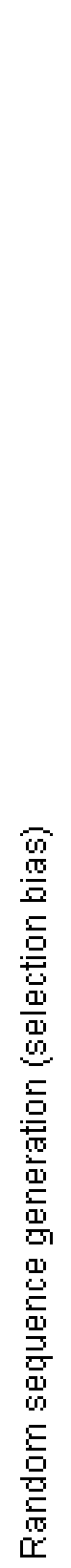 & 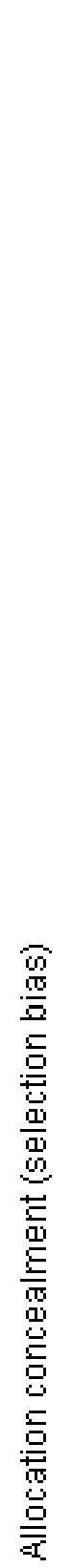 & 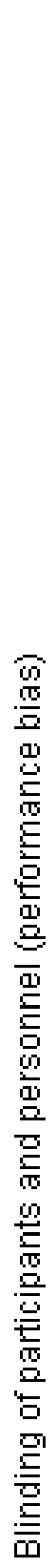 & 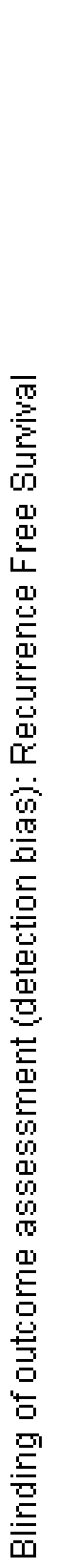 & 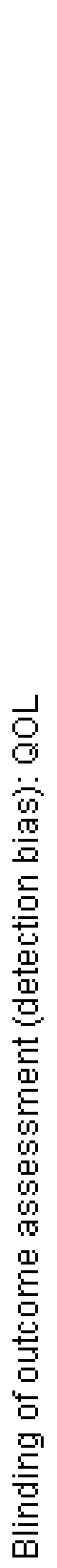 & 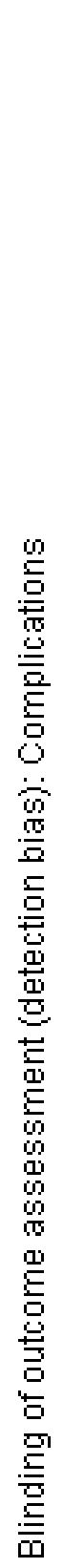 & 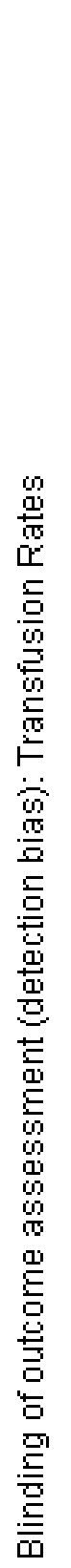 & 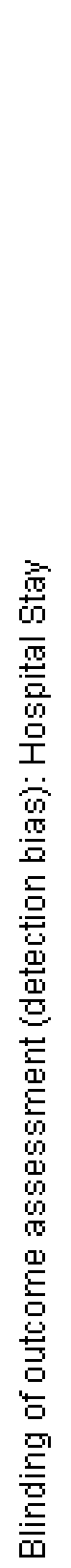 & 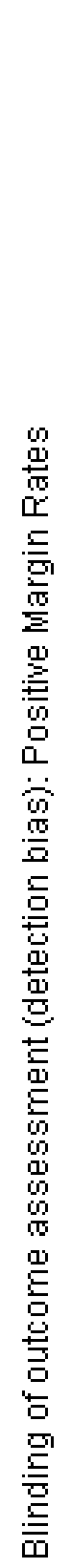 & 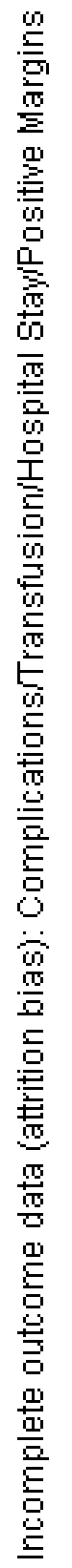 & 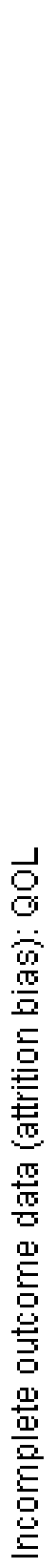 & 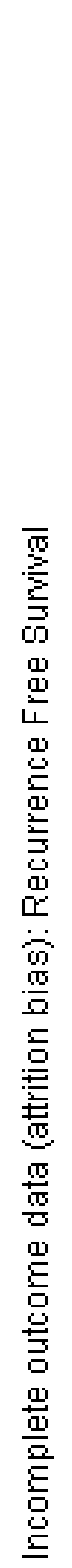 & 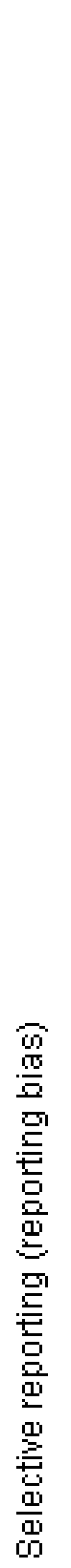 & 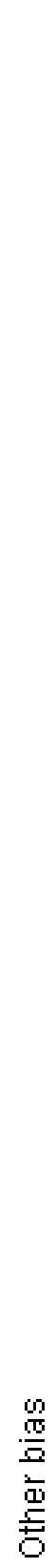 \\
\hline \multicolumn{15}{|l|}{ Bochner 2015} \\
\hline Khan 2016 & + & + & & $?$ & & & $?$ & 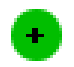 & $\oplus$ & + & & $?$ & + & + \\
\hline $\operatorname{Nix} 2010$ & + & & & $?$ & $?$ & $?$ & $?$ & 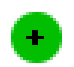 & + & + & $?$ & $?$ & $?$ & + \\
\hline Parekh 2013 & + & + & & $?$ & & $?$ & + & + & + & + & & $?$ & + & + \\
\hline Parekh 2018 & + & + & & & & & + & + & + & + & & $?$ & + & + \\
\hline
\end{tabular}




\section{Allocation}

\section{Random sequence generation}

We judged all five trials to have low risk of bias for random sequence allocation (Bochner 2015; Khan 2016; Nix 2010; Parekh 2013; Parekh 2018).

\section{Allocation concealment}

Nix 2010 performed a randomisation schema with five sequential participants undergoing one approach before alternating with another approach. Their concealment would have to be deemed inadequate and hence judged to be at high risk of bias. The remaining trials had low risk of bias in their allocation concealment strategy (Bochner 2015; Khan 2016; Parekh 2013; Parekh 2018).

\section{Blinding}

\section{Performance bias}

Due to the nature of the intervention (RARC vs ORC), it is considered unlikely that participants or personnel were blinded for any of the review outcomes. We therefore judged all included studies to be at high risk of performance bias.

\section{Detection bias}

\section{Time to recurrence}

Two trials reported on recurrence-free survival (Bochner 2015; Parekh 2018). Due to the lack of blinding of outcome assessors, we judged Parekh 2018 to be at high risk of detection bias for recurrence-free survival (Parekh 2018). We judged one trial as having unclear risk of detection bias for recurrence-free survival, as trial authors did not explicitly state who assessed this outcome (Bochner 2015).

\section{Complications (all grades)}

Three included studies were unblinded; we therefore judged them to be at high risk of detection bias for complications (Bochner 2015; Khan 2016; Parekh 2018). Two studies did not report who the assessors were and whether blinding had taken place; hence we judged them to be at unclear risk of detection bias for complications (Nix 2010; Parekh 2013).

\section{Quality of life}

In all four included studies, participants were not blinded; we therefore judged these trials to be at high risk of detection bias for the self-assessed outcome of quality of life survey (Bochner 2015; Khan 2016; Parekh 2013; Parekh 2018).

One study did not report quality of life data (Nix 2010).

\section{Positive margin rates, hospital stay, and transfusion rates}

The review authors opined that positive margin rates, hospital stay, and transfusion rates were unlikely to be affected by the blinding status of outcome assessors in these trials. We therefore judged all five studies to be at low risk of detection bias for positive surgical margin rates and hospital stay (Bochner 2015; Khan 2016; Nix 2010; Parekh 2013; Parekh 2018).
Nix 2010, Bochner 2015, and Khan 2016 did not report on transfusion rates. We judged Parekh 2018 and Parekh 2013 to be at low risk of detection bias for transfusion rates.

\section{Incomplete outcome data}

\section{Quality of life}

We judged four studies to be at high risk of attrition bias for quality of life survey results, given that a large proportion of participants (> 20\%) failed to provide information (Bochner 2015; Khan 2016; Parekh 2013; Parekh 2018).

\section{Major and minor postoperative complications, transfusion requirements, hospital stay, and positive margins}

We rated all studies as having low risk of attrition bias with near complete inclusion of randomised participants in analyses for these outcomes (Bochner 2015; Khan 2016; Nix 2010; Parekh 2013; Parekh 2018).

\section{Time to recurrrence}

We rated Bochner 2015 as having low risk of attrition bias, with all randomised participants included in the analysis. We rated Parekh 2018 as having unclear risk of attrition bias.

\section{Selective reporting}

Four studies had protocols registered in a trials registry (Bochner 2015; Khan 2016; Parekh 2013; Parekh 2018). We noted no obvious selective reporting for the outcomes of this review in these studies, and hence we judged them as having low risk of reporting bias. We were unable to find a protocol for the Nix 2010 trial. Therefore, we judged this trial as having an unclear risk of reporting bias.

\section{Other potential sources of bias}

We identified no other biases in any of the other included trials (Bochner 2015; Khan 2016; Nix 2010; Parekh 2013; Parekh 2018).

\section{Effects of interventions}

See: Summary of findings for the main comparison Roboticassisted laparoscopic vs open radical cystectomy for bladder cancer in adults

\section{Primary outcomes}

\section{Time to recurrence}

RARC may result in a similar time to recurrence as ORC (hazard ratio (HR) 1.05, 95\% confidence interval (Cl) 0.77 to 1.43 ); 2 trials; low-certainty evidence) (Figure 3). We downgraded the certainty of evidence for study limitations and imprecision (Analysis 1.1; Summary of findings for the main comparison). In absolute terms, this corresponds to 16 more recurrences per 1000 participants (95\% $\mathrm{Cl} 79$ fewer to 123 more). The control event rate at 5 years was based on an overall recurrence rate of $25 / 58(43.1 \%)$ in the ORC arm reported in Bochner 2015. 
Figure 3. Forest plot of comparison: 1 Primary Outcome, outcome: 1.1 Recurrence-Free Survival.

\begin{tabular}{|c|c|c|c|c|c|c|c|c|c|}
\hline \multirow[b]{2}{*}{ Study or Subgroup } & \multirow[b]{2}{*}{ log[Hazard Ratio] } & \multicolumn{2}{|c|}{ RARC } & \multicolumn{2}{|l|}{ ORC } & \multirow{2}{*}{$\begin{array}{c}\text { Hazard Ratio } \\
\text { IV, Random, 95\% CI }\end{array}$} & \multirow{2}{*}{\multicolumn{2}{|c|}{$\begin{array}{c}\text { Hazard Ratio } \\
\text { IV, Random, } 95 \% \mathrm{Cl}\end{array}$}} & Risk of Bias \\
\hline & & SE & Total & Total & Weight & & & & A B C D E F G H I \\
\hline Bochner 2015 & 0.239 & 0.284 & 60 & 58 & $31.5 \%$ & $1.27[0.73,2.22]$ & & & 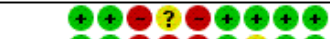 \\
\hline Parekh 2018 & -0.0408 & 0.1924 & 159 & 153 & $68.5 \%$ & $0.96[0.66,1.40]$ & & & $\Theta+? \oplus$ \\
\hline Total $(95 \% \mathrm{Cl})$ & & & 219 & 211 & $100.0 \%$ & $1.05[0.77,1.43]$ & & & \\
\hline $\begin{array}{l}\text { Heterogeneity: Tauz } \\
\text { Test for overall effect }\end{array}$ & $\begin{array}{l}0.00 ; C^{2}=0.67, d f \\
Z=0.30(P=0.77)\end{array}$ & $=1(P=$ & $1.41) ;\left.\right|^{2}$ & $=0 \%$ & & & 0.01 & 0.1 RARC ORC $^{10}$ & 100 \\
\hline
\end{tabular}

Risk of bias legend

(A) Random sequence generation (selection bias)

(B) Allocation concealment (selection bias)

(C) Blinding of participants and personnel (performance bias)

(D) Blinding of outcome assessment (detection bias): Recurrence Free Survival

(E) Blinding of outcome assessment (detection bias): QOL

(F) Incomplete outcome data (attrition bias): Complications/Transfusion/Hospital Stay/Positive Margins

(G) Incomplete outcome data (attrition bias): Recurrence Free Survival

(H) Selective reporting (reporting bias)

(l) Other bias

\section{Major complications (Clavien grades 3 to 5)}

RARC may result in similar rates of major complications as ORC (risk ratio (RR) $1.06,95 \% \mathrm{Cl} 0.76$ to 1.48 ); 5 trials; low-certainty evidence)
(Figure 4). This corresponds to 11 more major complications per 1000 participants ( $95 \% \mathrm{Cl} 44$ fewer to 89 more). We downgraded the certainty of evidence for study limitations and imprecision (Analysis 1.2; Summary of findings for the main comparison).

Figure 4. Forest plot of comparison: 1 Primary outcome, outcome: 1.1 Major postoperative complication rates (Clavien 3 to 5).

\begin{tabular}{|c|c|c|c|c|c|c|c|c|c|}
\hline \multirow[b]{2}{*}{ Study or Subgroup } & \multicolumn{2}{|c|}{ RARC } & \multicolumn{2}{|c|}{ ORC } & \multirow[b]{2}{*}{ Weight } & \multirow{2}{*}{$\begin{array}{c}\text { Risk Ratio } \\
\text { M-H, Random, } 95 \% \mathrm{Cl}\end{array}$} & \multirow{2}{*}{\multicolumn{2}{|c|}{$\begin{array}{c}\text { Risk Ratio } \\
\text { M-H, Random, } 95 \% \mathrm{Cl}\end{array}$}} & Risk of Bias \\
\hline & Events & Total & Events & Total & & & & & A B C D E F G H \\
\hline Bochner 2015 & 13 & 60 & 12 & 58 & $23.3 \%$ & $1.05[0.52,2.10]$ & & & \\
\hline Khan 2016 & 7 & 20 & 4 & 20 & $10.1 \%$ & $1.75[0.61,5.05]$ & & & \\
\hline Nix 2010 & 1 & 21 & 1 & 20 & $1.6 \%$ & $0.95[0.06,14.22]$ & & & \\
\hline Parekh 2013 & 1 & 20 & 1 & 20 & $1.6 \%$ & $1.00[0.07,14.90]$ & & & \\
\hline Parekh 2018 & 33 & 150 & 34 & 152 & $63.5 \%$ & $0.98[0.64,1.50]$ & & & \\
\hline Total $(95 \% \mathrm{Cl})$ & & 271 & & 270 & $100.0 \%$ & $1.06[0.76,1.48]$ & & & \\
\hline Total events & 55 & & 52 & & & & & & \\
\hline $\begin{array}{l}\text { Heterogeneity: Tau } \\
\text { Test for overall effec }\end{array}$ & $\begin{array}{l}0.00 ; \mathrm{Ch} \\
\mathrm{Z}=0.33\end{array}$ & $\begin{array}{l}2=0.99 \\
P=0.7\end{array}$ & $\begin{array}{l}9, d f=4( \\
5)\end{array}$ & $P=0.9$ & 1); $\left.\right|^{2}=0 \%$ & & 0.01 & $0.1{ }^{1}{ }^{10}$ & 100 \\
\hline
\end{tabular}

\author{
Risk of bias legend \\ (A) Random sequence generation (selection bias) \\ (B) Allocation concealment (selection bias) \\ (C) Blinding of participants and personnel (performance bias) \\ (D) Blinding of outcome assessment (detection bias): QOL \\ (E) Blinding of outcome assessment (detection bias): Complications \\ (F) Incomplete outcome data (attrition bias): Complications/Transfusion/Hospital Stay/Positive Margins \\ (G) Selective reporting (reporting bias) \\ (H) Other bias
}

Five trials reported on complications. Three studies reported the total number of Clavien grade 3 to 5 complications (Bochner 2015; Khan 2016; Parekh 2018). The other two studies reported specific complications (Nix 2010; Parekh 2013), based on which the review authors were able to classify complications by adopting the Clavien-Dindo grading system (Dindo 2004).

\section{Secondary outcomes}

\section{Minor complications (Clavien grades 1 and 2)}

We are very uncertain whether RARC results in fewer minor complications than ORC (RR $0.82,95 \% \mathrm{Cl} 0.58$ to $1.17 ; 4$ trials; very low-certainty evidence). This corresponds to 80 fewer minor complications per 1000 participants $(95 \% \mathrm{Cl} 186$ fewer to 75 more). We downgraded the certainty of evidence for serious study limitations and very serious imprecision (Analysis 1.3; Summary of findings for the main comparison).

\section{Transfusion rate}

RARC probably results in fewer transfusions than ORC (RR 0.58, $95 \% \mathrm{Cl} 0.43$ to $0.80 ; 2$ trials; moderate-certainty evidence). This corresponds to 193 fewer transfusions per 1000 participants (95\% $\mathrm{Cl} 262$ fewer to 92 fewer). We downgraded the certainty of evidence for study limitations (Analysis 1.4; Summary of findings for the main comparison). Only two studies reported on transfusion rates (Parekh 2013; Parekh 2018). 


\section{Length of hospital stay (days)}

All five trials provided information on hospital stay. One trial reported similar mean hospital stays of 5.1 days and 6 days in the RARC and ORC cohorts but did not report a standard deviation (Nix 2010). We therefore imputed the standard deviation. Two trials reported hospital stay in median and range values (Parekh 2013; Parekh 2018). We therefore imputed the mean and standard deviation for these trials. Two studies provided explicit data on mean hospital stay for meta-analysis (Bochner 2015; Khan 2016).

Overall, we found that RARC may reduce mean hospital stay slightly (mean difference (MD) $-0.67,95 \% \mathrm{Cl}-1.22$ to $-0.12 ; 5$ trials; low-certainty evidence). We downgraded the quality of evidence for study limitations and imprecision (Analysis 1.5; Summary of findings for the main comparison).

\section{Quality of life}

RARC may result in similar quality of life when compared with ORC (standard mean difference (SMD) 0.08, 95\% Cl: 0.32 lower to 0.16 higher; 3 trials; low-certainty evidence). We downgraded the certainty of evidence for study limitations and imprecision (Analysis 1.6; Summary of findings for the main comparison).

Four studies reported on quality of life (QoL) outcomes (Bochner 2015; Khan 2016; Parekh 2013; Parekh 2018). One trial used the European Organisation for Research and Treatment of Cancer (EORTC) Quality of Life Questionnaire Core 30 (QLQ-C30) survey (Bochner 2015). In this trial, data from the Global Health status domain were used for analysis, as this information reflected overall health status. One trial used the Functional Assessment of Cancer Therapy -Bladder (FACT-Bl) scale v4 and covered physical, emotional, and social well-being, as well as questions specific to bladder cancer (Khan 2016). Two trials used the Functional Assessment of Cancer Therapy -Vanderbilt Cystectomy Index (FACT-VCI) questionnaire (Parekh 2013; Parekh 2018). The standardised mean difference was used in view of the different QoL assessment tools used. One study reported QoL in median and range values (Parekh 2013). We therefore imputed mean and standard deviation for this study.

\section{Positive margin rates}

RARC may result in similar positive margin rates when compared to ORC (RR $1.16,95 \% \mathrm{Cl} 0.56$ to $2.40 ; 5$ trials; low-certainty evidence). This corresponds to eight more positive margins per 1000 participants ( $95 \% \mathrm{Cl} 21$ fewer to 67 more).

We downgraded the certainty of evidence for study limitations and imprecision (Analysis 1.7; Summary of findings for the main comparison).

We were unable to conduct any of the preplanned secondary analyses due to lack of suitable data.

\section{DISCUSSION}

\section{Summary of main results}

There may be little to no difference in time to recurrence and in risk of major complications between the two surgical approaches to treat muscle-invasive bladder cancer. We are very uncertain whether RARC reduces the rate of minor complications. There may be little to no difference in quality of life and positive margin rates.
RARC probably reduces transfusions substantially and may reduce length of stay slightly.

\section{Overall completeness and applicability of evidence}

Follow-up of the included trials is generally limited; only one trial has reported longer-term follow-up for the outcome of recurrencefree survival at a median follow-up of 4.9 years (Bochner 2015). Another trial reported on progression-free survival at two years (Parekh 2018). Review authors judged this trial to have high risk of performance and detection bias for recurrence-free survival. One small trial provided data on recurrence rates and overall and disease-specific mortality at 12 months (Khan 2016). We judged this trial to have high risk of performance, detection, attrition, and reporting bias. Follow-up was very short, at 12 months, further emphasising the lack of vital long-term oncological data derived from randomised controlled trials (RCTs) comparing open radical cystectomy (ORC) and robotic-assisted radical cystectomy (RARC).

All studies reported on complication rates. However, two studies did not demonstrate clear categorisation into minor and major complications using the Clavien-Dindo grading system, as suggested by this review (Nix 2010; Parekh 2013). We therefore examined individual complications reported by these trials and classified them using the Clavien-Dindo grading system. Although data show no obvious differences between ORC and RARC for major complications, the outcomes again were of low quality, suggesting significant uncertainty of the results, and hence must be viewed with caution.

For the outcomes "hospital stay" and "quality of life", three studies reported unfavourable metrics and statistical methods (e.g. median, no standard deviations reported for means) for metaanalysis (Nix 2010; Parekh 2013, Parekh 2018). The review authors therefore imputed these data.

\section{Quality of the evidence}

We rated the certainty of evidence as low for all outcomes, except transfusion rates and hospital stay. We consistently downgraded evidence for a combination of study limitations, most often performance bias (lack of blinding of participants and personnel) and detection bias (lack of blinding of outcome assessors). We also frequently downgraded evidence for imprecision due to wide confidence intervals that indicated no effect but also included the possibility of clinically relevant benefit or harm.

\section{Potential biases in the review process}

We performed this systematic review in accordance with current Cochrane standards. The review nevertheless has the following limitations:

- The review authors cannot be absolutely certain if we missed identifying any other potential randomised trials comparing ORC and RARC in our search, although we think this is unlikely.

- We excluded from the meta-analysis some of the data reported by individual studies due to lack of appropriate data points. We contacted the authors of these individual studies but were not successful in obtaining additional data. We chose to impute data in accordance with the editorial policy of Cochrane standards. 


\section{Agreements and disagreements with other studies or reviews}

We identified five relevant systematic reviews of randomised and nonrandomised controlled trials comparing robotic and open radical cystectomy (Ishii 2014; Novara 2015; Tang 2014; Yuh 2015; Sathianathen 2018). These reviews used pooled data derived across all study designs, and none considered evaluation of the quality of evidence as defined by GRADE.

Yuh 2015 performed a cumulative analysis of oncological and functional outcomes of robotic-assisted radical cystectomy (RARC). This review identified 65 surgical series and 22 comparative studies reporting on pathological, oncological, and functional outcomes of RARC. Two trials in the review were randomised trials (Nix 2010; Parekh 2013). We included both of these studies in our review. A majority of the studies included in this review were retrospective studies. No certainty of evidence was assessed. The review identified two nonrandomised comparative studies that reported similar survival outcomes between ORC and RARC (Khan 2012; Nepple 2013). Review authors suggested caution when interpreting these results due to short follow-up, small series, and study limitations.

Novara 2015 performed a cumulative analysis of perioperative outcomes and postoperative complications of RARC. This review identified 70 surgical series and 23 comparative studies. Three trials included in the review were randomised trials (Bochner 2015; Nix 2010; Parekh 2013). We have included these three studies in our review. A majority of studies included in the Novara review were retrospective studies. Review authors categorised individual studies to the 2011 level of evidence and IDEAL recommendations and scrutinised the quality of reporting of complications of individual studies using the Martin criteria (Martin 2002). They performed no other quality assessment of individual studies. These review authors reported 90-day complication rates of any grade and found that 90 -day grade 3 complication rates were lower for RARC, whereas high-grade complication and mortality rates were similar. It is unclear from the review how the review authors differentiated between grade 3 complications and highgrade complications. The analysis for grade 3 complications did not include any of the RCTs. The analysis for high-grade complications included one RCT (Bochner 2015). The RCT included in this analysis contributed $19.3 \%$ to the study weight.

Tang 2014 performed a systematic review that included 13 studies comparing RARC and ORC. One trial in the review was a randomised trial (Nix 2010). We have included this study in our review. These review authors reported perioperative and pathological outcomes and complications. Review authors pooled data across all study designs. They rated the level of evidence (LOE) of included studies according to criteria provided by the Centre for Evidence-Based Medicine in Oxford, UK. They assessed risk of bias of the RCT using the Jadad scale and of observational studies using the NewcastleOttawa scale. Pooled analysis favoured the RARC cohort for overall complication rate. Nix 2010, the only RCT included in the analysis, contributed only $5.5 \%$ to the study weight.

Ishii 2014 performed a systematic review that included seven studies comparing RARC and ORC. Two trials in the review were randomised trials (Nix 2010; Parekh 2013). We have included both of these studies in our review. Review authors assessed the methodological quality of these included studies in line with the Cochrane Handbook for Systematic Reviews of Interventions. The primary outcome of this study was complication rates. Pooled analysis favoured the RARC cohort for major complication rates. Analysis for major complications included one RCT (Parekh 2013), which contributed to $6.7 \%$ to the study weight.

Sathianathen 2018 has published the most recent and highestquality review to date. Methodolgical hallmarks include an a priori registered protocol with predefined primary outcomes, a comprehensive search of multiple data sources, and study inclusion irrespective of language of publication status and use of GRADE to assess the quality of evidence on a per-outcome basis. Instead of recurrence-free survival as a time-to-event outcome used in our review, these review authors analysed risk of recurrence as a dichotomous outcome. They rated findings as moderatequality evidence, which is more optimistic than our rating of lowquality evidence, while qualifying that there is little to no difference between the two approaches. What our review further adds is a summary of findings table (Summary of findings for the main comparison) with corresponding absolute effect size estimates.

\section{AUTHORS' CONCLUSIONS}

\section{Implications for practice}

Based on the findings of this review, oncological outcomes and rates of major complications may be similar for both approaches. Robotic-assisted cystectomy probably reduces transfusion needs substantially and may slightly reduce length of hospital stay. We are uncertain whether minor complications are also reduced. We were unable to address how patients' and surgeons' characteristics may affect these outcomes. Furthermore, this review was not designed to address resource utilisation or cost-effectiveness.

\section{Implications for research}

This review is based on five relatively small trials with methodological limitations that provided low-quality evidence for most outcomes. Only one trial has provided long-term oncological outcomes (Bochner 2015). We see the following research needs:

- Investigators of existing trials should report longer-term results for longer-term oncological outcomes.

- Researchers should assess the influence of patient factors such as pathological stage and body habitus.

- Studies should establish the impact of surgeon factors such as skills and experience on outcomes.

- Most instances of urinary diversion reported in included trials were performed through an extracorporeal approach. Future trials should evaluate outcomes between open radical cystectomy and robotic-assisted radical cystectomy performed through intracorporeal urinary diversions.

- Any future trial should apply widely accepted methodological safeguards against bias and should transparently report them.

\section{ACK N O WLEDGEMENTS}

We would like to thank the editors of Cochrane Urology for the support they provided. 


\section{R E F E R E N C E S}

\section{References to studies included in this review}

\section{Bochner 2015 \{published data only\}}

Bochner BH, Dalbagni G, Marzouk KH, Sjoberg DD, Lee J, Donat SM, et al. Randomized trial comparing open radical cystectomy and robot-assisted laparoscopic radical cystectomy: oncologic outcomes. European Urology 2018;74(4):465-71. [PUBMED: 29784190]

Bochner BH, Dalbagni G, Sjoberg DD, Silberstein J, Keren Paz GE, Donat SM, et al. Comparing open radical cystectomy and robot-assisted laparoscopic radical cystectomy: a randomized clinical trial. European Urology 2015;67(6):1042-50.

\section{Khan 2016 \{published data only\}}

Khan MS, Gan C, Ahmed K, Ismail AF, Watkins J, Summers JA, et al. A single-centre early phase randomised controlled threearm trial of open, robotic, and laparoscopic radical cystectomy (CORAL). European Urology 2016;69(4):613-21.

\section{Nix 2010 \{published data only\}}

Nix J, Smith A, Kurpad R, Nielsen ME, Wallen EM, Pruthi RS Prospective randomized controlled trial of robotic versus open radical cystectomy for bladder cancer: perioperative and pathologic results. European Urology 2010;57(2):196-201.

\section{Parekh 2013 \{published data only\}}

Messer JC, Punnen S, Fitzgerald J, Svatek R, Parekh DJ. Healthrelated quality of life from a prospective randomised clinical trial of robot-assisted laparoscopic versus open radical cystectomy. BJU International 2014;114(6):896-902.

Parekh DJ, Messer J, Fitzgerald J, Ercole B, Svatek R. Perioperative outcomes and oncologic efficacy from a pilot prospective randomized clinical trial of open versus robotic assisted radical cystectomy. Journal of Urology 2013;189(2):474-9.

\section{Parekh 2018 \{published data only\}}

* Parekh DJ, Reis IM, Castle EP, Gonzalgo ML, Woods ME, Svatek RS, et al. Robot-assisted radical cystectomy versus open radical cystectomy in patients with bladder cancer (RAZOR): an open-label, randomised, phase 3, non-inferiority trial. Lancet 2018;391:2525-36.

\section{References to studies excluded from this review}

\section{Anderson 2013 \{published data only\}}

Anderson CB, Morgan TM, Kappa S, Moore D, Clark PE, Davis R, et al. Ureteroenteric anastomotic strictures after radical cystectomy - does operative approach matter?. Journal of Urology 2013;189(2):541-7.

\section{Atmaca 2015 \{published data only\}}

Atmaca AF, Canda AE, Gok B, Akbulut Z, Altinova S, Balbay MD. Open versus robotic radical cystectomy with intracorporeal Studer diversion. Journal of the Society of Laparoendoscopic Surgeons 2015;19(1):e2014.00193. [PUBMED: 25848187]
Bak 2016 \{published data only\}

Bak DJ, Lee YJ, Woo MJ, Chung JW, Ha YS, Kim HT, et al. Complications and oncologic outcomes following robotassisted radical cystectomy: what is the real benefit?. Investigative and Clinical Urology 2016;57(4):260-7. [PUBMED: 27437535]

\section{Borza 2017 \{published data only\}}

Borza T, Jacobs BL, Montgomery JS, Weizer AZ, Morgan TM, Hafez KS, et al. No differences in population-based readmissions after open and robotic-assisted radical cystectomy: implications for post-discharge care. Urology 2017;104:77-83. [PUBMED: 28267606]

\section{Cusano 2016 \{published data only\}}

Cusano A, Haddock P Jr, Jackson M, Staff I, Wagner J, Meraney A. A comparison of preliminary oncologic outcome and postoperative complications between patients undergoing either open or robotic radical cystectomy. International Brazilian Journal of Urology 2016;42(4):663-70. [PUBMED: 27564275]

\section{Galich 2006 \{published data only\}}

Galich A, Sterrett S, Nazemi T, Pohlman G, Smith L, Balaji KC. Comparative analysis of early perioperative outcomes following radical cystectomy by either the robotic or open method. Journal of the Society of Laparoendoscopic Surgeons 2006;10(2):145-50.

\section{Gandaglia 2016 \{published data only\}}

Gandaglia G, Karl A, Novara G, de Groote R, Buchner A, D'Hondt $F$, et al. Perioperative and oncologic outcomes of robot-assisted versus open radical cystectomy in bladder cancer patients: a comparison of two high-volume referral centers. European Journal of Surgical Oncology 2016;42(11):1736-43. [PUBMED: 27032295]

\section{Ginot 2016 \{published data only\}}

Ginot R, Rouget B, Bensadoun H, Pasticier G, Bernhard JC, Capon G, et al. Radical cystectomy with orthotopic neobladder replacement: comparison of robotic assisted and open surgical route [Cystectomie totale avec remplacement vesical orthotopique: comparaison des resultats des patients operes par voie ouverte et par voie coelioscopique robot-assistee.]. Progres en Urologie 2016;26(8):457-63. [PUBMED: 27460787]

\section{Gondo 2012 \{published data only\}}

Gondo T, Yoshioka K, Nakagami Y, Okubo H, Hashimoto T, Satake N, et al. Robotic versus open radical cystectomy: prospective comparison of perioperative and pathologic outcomes in Japan. Japanese Journal of Clinical Oncology 2012;42(7):625-31.

\section{Khan 2012 \{published data only\}}

Khan MS, Challacombe B, Elhage O, Rimington P, Coker B, Murphy D, et al. A dual-centre, cohort comparison of open, laparoscopic and robotic-assisted radical cystectomy. International Journal of Clinical Practice 2012;66(7):656-62. 


\section{Koupparis 2015 \{published data only\}}

Koupparis A, Villeda-Sandoval C, Weale N, El-Mahdy M, Gillatt D, Rowe E. Robot-assisted radical cystectomy with intracorporeal urinary diversion: impact on an established enhanced recovery protocol. BJU International 2015;116(6):924-31. [PUBMED: 25943158]

\section{Lee 2011 \{published data only\}}

Lee R, Ng CK, Shariat SF, Borkina A, Guimento R, Brumit KF, et al. The economics of robotic cystectomy: cost comparison of open versus robotic cystectomy. BJU International 2011;108(11):1886-92.

\section{Li 2016 \{published data only\}}

Li AY, Filson CP, Hollingsworth JM, He C, Weizer AZ, Hollenbeck BK, et al. Patient-reported convalescence and quality of life recovery: a comparison of open and robotic-assisted radical cystectomy. Surgical Innovation 2016;23(6):598-605. [PUBMED: 27354552]

Martin 2011 \{published data only\}

Martin AD, Nunez RN, Castle EP. Robot-assisted radical cystectomy versus open radical cystectomy: a complete cost analysis. Urology 2011;77(3):621-5.

\section{Matulewicz 2016 \{published data only\}}

Matulewicz RS, DeLancey JO, Manjunath A, Tse J, Kundu SD, Meeks JJ. National comparison of oncologic quality indicators between open and robotic-assisted radical cystectomy. Urologic Oncology 2016;34(10):431.e9-431.e15. [PUBMED: 27264169]

\section{Musch 2014 \{published data only\}}

Musch M, Janowski M, Steves A, Roggenbuck U, Boergers A, Davoudi $Y$, et al. Comparison of early postoperative morbidity after robot-assisted and open radical cystectomy: results of a prospective observational study. BJU international 2014;113(3):458-67.

\section{Nepple 2013 \{published data only\}}

Nepple KG, Strope SA, Grubb RL 3rd, Kibel AS. Early oncologic outcomes of robotic versus open radical cystectomy for urothelial cancer. Urologic Oncology 2013;31(6):894-8. [PUBMED: 21803615]

\section{Ng 2010 \{published data only\}}

Ng CK, Kauffman EC, Lee MM, Otto BJ, Portnoff A, Ehrlich JR, et al. A comparison of postoperative complications in open versus robotic cystectomy. European Urology 2010;57(2):274-82.

\section{Nguyen 2015 \{published data only\}}

Nguyen DP, Al Hussein Al Awamlh B, Wu X, O'Malley P, Inoyatov IM, Ayangbesan $A$, et al. Recurrence patterns after open and robot-assisted radical cystectomy for bladder cancer. European Urology 2015;68(3):399-405. [PUBMED: 25709026]

\section{Rhee 2006 \{published data only\}}

Rhee JJ, Lebeau S, Smolkin M, Theodorescu D. Radical cystectomy with ileal conduit diversion: early prospective evaluation of the impact of robotic assistance. BJU International 2006;98(5):1059-63.

\section{Satkunasivam 2016 \{published data only\}}

Satkunasivam R, Santomauro M, Chopra S, Plotner E, Cai J, Miranda G, et al. Robotic intracorporeal orthotopic neobladder: urodynamic outcomes, urinary function, and health-related quality of life. European Urology 2016;69(2):247-53. [PUBMED: 26164417]

\section{Sharma 2017 \{published data only\}}

Sharma P, Zargar-Shoshtari K, Poch MA, Pow-Sang JM, Sexton WJ, Spiess PE, et al. Surgical control and margin status after robotic and open cystectomy in high-risk cases: caution or equivalence?. World Journal of Urology 2017;35(4):657-63. [PUBMED: 27495912]

\section{Styn 2012 \{published data only\}}

Styn NR, Montgomery JS, Wood DP, Hafez KS, Lee CT, Tallman C, et al. Matched comparison of robotic-assisted and open radical cystectomy. Urology 2012;79(6):1303-9.

\section{Tan 2016 \{published data only\}}

Tan WS, Sridhar A, Ellis G, Lamb B, Goldstraw M, Nathan S, et al. Analysis of open and intracorporeal robotic assisted radical cystectomy shows no significant difference in recurrence patterns and oncological outcomes. Urologic Oncology 2016;34(6):257.e1-9. [PUBMED: 26968561]

Wang 2008 \{published data only\}

Wang GJ, Barocas DA, Raman JD, Scherr DS. Robotic vs open radical cystectomy: prospective comparison of perioperative outcomes and pathological measures of early oncological efficacy. BJU International 2008;101(1):89-93.

\section{Winters 2016 \{published data only\}}

Winters BR, Bremjit PJ, Gore JL, Lin DW, Ellis WJ, Dalkin BL, et al. Preliminary comparative effectiveness of robotic versus open radical cystectomy in elderly patients. Journal of Endourology 2016;30(2):212-7. [PUBMED: 26414964]

\section{References to ongoing studies}

\section{Kelly , Catto 2017 \{published data only\}}

Kelly J, Catto J. Trial to compare robotically assisted radical cystectomy with open radical cystectomy (iROC). https:// clinicaltrials.gov/ct2/show/NCT03049410 (accessed 7 June 2017).

\section{Additional references}

\section{Aboumarzouk 2012}

Aboumarzouk OM, Drewa T, Olejniczak P, Chlosta PL. Laparoscopic radical cystectomy: a 5-year review of a single institute's operative data and complications and a systematic review of the literature. International Brazilian Journal of Urology 2012;38(3):330-40.

\section{Aboumarzouk 2013}

Aboumarzouk OM, Hughes O, Narahari K, Drewa T, Chlosta PL, Kynaston H. Safety and feasibility of laparoscopic radical cystectomy for the treatment of bladder cancer. Journal of Endourology / Endourological Society 2013;27(9):1083-95. 


\section{Ballantyne 2003}

Ballantyne GH, Moll F. The da Vinci telerobotic surgical system: the virtual operative field and telepresence surgery. Surgical Clinics of North America 2003;83(6):1293-304, vii.

\section{Castillo 2006}

Castillo OA, Abreu SC, Mariano MB, Tefilli MV, Hoyos J, Pinto I, et al. Complications in laparoscopic radical cystectomy: the South American experience with 59 cases. International Brazilian Journal of Urology 2006;32(3):300-5.

\section{Castillo 2009}

Castillo OA, Vitagliano G, Vidal-Mora I. Laparoscopic radical cystectomy: the new gold standard for bladder carcinoma?. Archivos Espanoles de Urologia 2009;62(9):737-44.

\section{Cathelineau 2005}

Cathelineau X, Arroyo C, Rozet F, Barret E, Vallancien G. Laparoscopic assisted radical cystectomy: the Montsouris experience after 84 cases. European Urology 2005;47(6):780-4.

\section{Dindo 2004}

Dindo D, Demartines N, Clavien PA. Classification of surgical complications: a new proposal with evaluation in a cohort of 6336 patients and results of a survey. Annals of Surgery 2004;240(2):205-13.

\section{Ferlay 2013}

Ferlay J, Soerjomataram I, Ervik M, Dikshit R, Eser S, Mathers C, et al. GLOBOCAN 2012 v1.0, Cancer Incidence and Mortality Worldwide: IARC CancerBase No. 11. Lyon, France: International Agency for Research on Cancer; 2013. globocan.iarc.fr (accessed 5 June 2015).

\section{Ferlay 2015}

Ferlay J, Soerjomataram I, Dikshit R, Eser S, Mathers C, Rebelo $\mathrm{M}$, et al. Cancer incidence and mortality worldwide: sources, methods and major patterns in GLOBOCAN 2012. International Journal of Cancer 2015;136(5):E359-86.

\section{GRADEpro GDT}

GRADEpro GDT: GRADEpro Guideline Development Tool [Software]. Hamilton (ON): McMaster University, 2015 (developed by Evidence Prime, Inc.). Available from www.gradepro.org.

\section{Guyatt 2008}

Guyatt GH, Oxman AD, Vist GE, Kunz R, Falck-Ytter Y, Schünemann HJ, et al. GRADE: what is "quality of evidence" and why is it important to clinicians?. BMJ (Clinical Research Ed) 2008;336(7651):995-8. [DOI: 10.1136/bmj.39490.551019.BE]

\section{Guyatt 2011}

Guyatt G, Oxman AD, Akl EA, Kunz R, Vist G, Brozek J, et al. GRADE guidelines: 1 . Introduction - GRADE evidence profiles and summary of findings tables. Journal of Clinical Epidemiology 2011;64(4):383-94. [DOI: 10.1016/ j.jclinepi.2010.04.026]

\section{Haber 2008}

Haber GP, Crouzet S, Gill IS. Laparoscopic and robotic assisted radical cystectomy for bladder cancer: a critical analysis. European Urology 2008;54(1):54-62.

\section{Hayn 2010}

Hayn MH, Hussain A, Mansour AM, Andrews PE, Carpentier P, Castle $E$, et al. The learning curve of robot-assisted radical cystectomy: results from the International Robotic Cystectomy Consortium. European Urology 2010;58(2):197-202.

\section{Higgins 2003}

Higgins JP, Thompson SG, Deeks JJ, Altman DG. Measuring inconsistency in meta-analyses. BMJ (Clinical Research Ed.) 2003;327(7414):557-60. [MEDLINE: 12958120]

\section{Higgins 2011}

Higgins JPT, Green S (editors). Cochrane Handbook for Systematic Reviews of Interventions. Version 5.1.0 [updated March 2011]. The Cochrane Collaboration, 2011. Available from www.cochrane-handbook.org.

\section{Hosseini 2011}

Hosseini A, Adding C, Nilsson A, Jonsson MN, Wiklund NP. Robotic cystectomy: surgical technique. BJU International 2011;108(6b):962-8.

\section{Hozo 2005}

Hozo SP, Djulbegovic B, Hozo I. Estimating the mean and variance from the median, range, and the size of a sample. $B M C$ Medical Research Methodology 2005;5:13. [PUBMED: 15840177]

\section{Hu 2009}

Hu JC, Gu X, Lipsitz SR, Barry MJ, D'Amico AV, Weinberg AC, et al. Comparative effectiveness of minimally invasive versus open radical prostatectomy. JAMA 2009;302(14):1557-64. [PUBMED: 19826025]

\section{Huang 2008}

Huang J, Lin T, Xu K, Huang H, Jiang C, Han J, et al. Laparoscopic radical cystectomy with orthotopic ileal neobladder: a report of 85 cases. Journal of Endourology / Endourological Society 2008;22(5):939-46.

\section{Huang 2010}

Huang J, Lin T, Liu H, Xu K, Zhang C, Jiang C, et al. Laparoscopic radical cystectomy with orthotopic ileal neobladder for bladder cancer: oncologic results of 171 cases with a median 3-year follow-up. European Urology 2010;58(3):442-9.

\section{Ishii 2014}

Ishii H, Rai BP, Stolzenburg JU, Bose P, Chlosta PL, Somani BK, et al. Robotic or open radical cystectomy, which is safer? A systematic review and meta-analysis of comparative studies. Journal of Endourology / Endourological Society 2014;28(10):1215-23. [PUBMED: 25000311]

\section{Jonsson 2011}

Jonsson MN, Adding LC, Hosseini A, Schumacher MC, Volz D, Nilsson A, et al. Robot-assisted radical cystectomy with intracorporeal urinary diversion in patients with 
transitional cell carcinoma of the bladder. European Urology 2011;60(5):1066-73.

\section{Khan 2011}

Khan MS, Elhage O, Challacombe B, Rimington P, Murphy D, Dasgupta P. Analysis of early complications of robotic-assisted radical cystectomy using a standardized reporting system. Urology 2011;77(2):357-62.

\section{Liberati 2009}

Liberati A, Altman DG, Tetzlaff J, Mulrow C, Gøtzsche PC, loannidis JPA, et al. The PRISMA statement for reporting systematic reviews and meta-analyses of studies that evaluate health care interventions: explanation and elaboration. PLoS Medicine 2009;6(7):e1000100. [DOI: 10.1371/ journal.pmed.1000100]

\section{Martin 2002}

Martin RC 2nd, Brennan MF, Jaques DP. Quality of complication reporting in the surgical literature. Annals of Surgery 2002;235(6):803-13. [PUBMED: 12035036]

\section{Novara 2012}

Novara G, Ficarra V, Rosen RC, Artibani W, Costello A, Eastham JA, et al. Systematic review and meta-analysis of perioperative outcomes and complications after robot-assisted radical prostatectomy. European Urology 2012;62(3):431-52.

\section{Novara 2015}

Novara G, Catto JW, Wilson T, Annerstedt M, Chan K, Murphy DG, et al. Systematic review and cumulative analysis of perioperative outcomes and complications after robot-assisted radical cystectomy. European Urology 2015;67(3):376-401.

\section{Ploeg 2009}

Ploeg M, Aben KK, Kiemeney LA. The present and future burden of urinary bladder cancer in the world. World Journal of Urology 2009;27(3):289-93.

\section{Raza 2015}

Raza SJ, Wilson T, Peabody JO, Wiklund P, Scherr DS, Al-Daghmin A, et al. Long-term oncologic outcomes following robot-assisted radical cystectomy: results from the International Robotic Cystectomy Consortium. European Urology 2015;68(4):721-8. [PUBMED: 25985883]

\section{Redorta 2010}

Redorta JP, Gaya JM, Breda A, Gausa L, Rodríguez O, Villavicencio H. Robotic cystectomy versus open cystectomy: are we there yet?. European Urology Supplements 2010;9(3):433-7.

\section{RevMan [Computer program]}

The Nordic Cochrane Centre, The Cochrane Collaboration. Review Manager 5 (RevMan 5). Version 5.3. Copenhagen: The Nordic Cochrane Centre, The Cochrane Collaboration, 2014.

\section{Sathianathen 2018}

Sathianathen NJ, Kalapara A, Frydenberg M, Lawrentschuk N, Weight, C, Parek D, Konety BR. Robotic-assisted radical cystectomy vs open radical cystectomy: systematic review and meta-analysis. Journal of Urology 2018/10/16;201(4):715-720. [PUBMED: 30321551]

\section{Schwenk 2005}

Schwenk W, Haase O, Neudecker J, Muller JM. Short term benefits for laparoscopic colorectal resection. Cochrane Database of Systematic Reviews 2005;3:CD003145. [PUBMED: 16034888]

\section{Shabsigh 2009}

Shabsigh A, Korets R, Vora KC, Brooks CM, Cronin AM, Savage C, et al. Defining early morbidity of radical cystectomy for patients with bladder cancer using a standardized reporting methodology. European urology 2009;55(1):164-74. [PUBMED: 18675501]

\section{Sighinolfi 2007}

Sighinolfi MC, Micali S, Celia A, DeStefani S, Grande M, Rivalta M, et al. Laparoscopic radical cystectomy: an Italian survey. Surgical Endoscopy 2007;21(8):1308-11.

\section{Smith 2011}

Smith AB, Raynor MC, Pruthi RS. Peri- and postoperative outcomes of robot-assisted radical cystectomy (RARC). BJU International 2011;108(6 Pt 2):969-75.

\section{Tang 2014}

Tang K, Xia D, Li H, Guan W, Guo X, Hu Z, et al. Robotic vs. open radical cystectomy in bladder cancer: a systematic review and meta-analysis. European Journal of Surgical Oncology 2014;40(11):1399-411. [PUBMED: 24767803]

\section{Witjes 2014}

Witjes JA, Comperat E, Cowan NC, De Santis M, Gakis G, Lebret T, et al. EAU guidelines on muscle-invasive and metastatic bladder cancer: summary of the 2013 guidelines. European Urology 2014;65(4):778-92. [PUBMED: 24373477]

\section{Wright 2013}

Wright JD, Ananth CV, Lewin SN, Burke WM, Lu YS, Neugut Al, et al. Robotically assisted versus laparoscopic hysterectomy among women with benign gynecologic disease. JAMA 2013;309(7):689-98. [PUBMED: 23423414]

\section{Yuh 2015}

Yuh B, Wilson T, Bochner B, Chan K, Palou J, Stenzl A, et al. Systematic review and cumulative analysis of oncologic and functional outcomes after robot-assisted radical cystectomy. European Urology 2015;67(3):402-22. [PUBMED: 25560797]

* Indicates the major publication for the study

\section{CHARACTERISTICS OF STUDIES}

\section{Characteristics of included studies [ordered by study ID]}


Bochner 2015

- Study design: parallel RCT, expertise-based, superiority trial
- Study date: March 2010 to March 2013
- Study setting: hospital-based, single-institution study -Memorial Sloan Kettering Cancer Center
(MSKCC), USA
- Randomisation ratio: $1: 1$
- Study hypothesised that the rate of Clavien grade 2 to 5 complications would be $20 \%$ lower in absolute
terms for RARC compared with ORC. This trial with an a of $5 \%$ and $80 \%$ power would require 93 par-
ticipants per arm. However, due to a mandated interim analysis to occur halfway through enrolment,
the study intended to accrue 105 participants per arm to maintain $80 \%$ power. For the interim analy-
sis, study authors would calculate the upper bound of a one-sided $95 \%$ CI for the difference in rate of
Clavien grade 2 to 5 complications between surgery groups. If the upper bound was $20 \%$, they would
stop the trial for futility.

Participants

\section{Adults undergoing radical cystectomy $(n=118)$ \\ Diagnostic criteria:}

- Bladder cancer with clinical stage Ta-T3/N0-3/M0

\section{Inclusion criteria:}

- Medically cleared for RC plus PLND

- Aged 18 years

- Clinical stage Ta-T3/N0-3/M0

\section{Exclusion criteria:}

- Previous pelvic radiation

- Clinical stage T4 or M1

- Any contraindication for Trendelenburg position, or extensive prior abdominal surgery

\section{Demographic data: RARC vs ORC}

Median age years (IQR) $=66$ (60 to 71$)$ vs 65 (58 to 69)

Male sex, $\mathrm{n}(\%)=51(85)$ vs $42(72)$

Body mass index, $\mathrm{kg} / \mathrm{m}^{2}$, median $(\mathrm{IQR})=27.9$ (24.7 to 31.0$)$ vs 29.0 (26.3 to 33.7 )
Cohort $1=$ ORC with urinary diversion and PLND $(n=58)$

Cohort 2 = RARC with extracorporeal urinary diversion and PLND $(n=60)$

- Men underwent removal of the prostate if present, and women underwent hysterectomy and bilateral salpingo-oophorectomy if organs were present.

- Lymphadenectomy template: The extent of the PLND was left to the discretion of the surgeon based on clinician preference and judgement (extent of disease, vascular disease) and was determined before randomisation. The extent of PLND was alterable intraoperatively based on clinical findings (vascular disease, fibrosis, adenopathy).

- Surgeon experience: This is an expertise-based study. All RARC procedures were performed by 1 of 3 surgeons with extensive robotic pelvic surgery experience. All urinary diversions were performed as open surgeries; therefore, 1 of the surgeons experienced in open procedures completed them, regardless of the randomisation arm. All surgeons were urological oncology fellowship trained and had a minimum of 10 years' operative experience in practice after fellowship.

- Number of conversions from RARC to ORC: 0

- Number of participant crossovers to ORC after randomising to RARC: 4 (patient refusal to have RARC)

\section{Outcomes}

- Primary outcomes

- Overall 90-day grade 2 to 5 complications defined by a modified Clavien system 
Bochner 2015 (Continued)

- Secondary outcomes included

- Comparison of high-grade complications

- Estimated blood loss

- Operative time

- Pathological outcomes

- 3- and 6-month patient-reported QoL outcomes

- Total operative room and inpatient costs

- ITT analysis performed

Funding sources

This study was supported by the Sidney Kimmel Center for Prostate and Urologic Cancers at Memorial Sloan Kettering Cancer Center, Pin Down Bladder Cancer, and the Michael and Zena Wienerfor Therapeutics Program in Bladder Cancer. Study sponsors were involved in the design and conduct of the study; in collection, analysis, management, and interpretation of the data; and in preparation, review, and approval of the manuscript.

\begin{tabular}{ll}
\hline Declarations of interest & None \\
\hline Notes & Language of publication: English \\
\hline
\end{tabular}

\section{Risk of bias}

\begin{tabular}{lll}
\hline Bias & Authors' judgement & Support for judgement \\
\hline $\begin{array}{ll}\text { Random sequence genera- } \\
\text { tion (selection bias) }\end{array}$ & Low risk & $\begin{array}{l}\text { Quote from publication: "Consenting patients were stratified by age (64 vs 65 } \\
\text { yr) and American Society of Anesthesiologists score (1-2 vs 3-4), then random- } \\
\text { ly assigned } 1: 1 \text { to undergo RARC or ORC using randomly permuted blocks of } \\
\text { random length." }\end{array}$
\end{tabular}

Comment: adequate random sequence generation performed

$\begin{array}{ll}\begin{array}{l}\text { Allocation concealment } \\ \text { (selection bias) }\end{array} & \text { Quote from publication: "Randomization was conducted by an independent } \\ & \text { office, where allocation concealment was ensured by a password-protected } \\ \text { database, such that the randomization group could not be predicted prior to } \\ \text { receiving group assignment and group could not be changed after randomiza- } \\ \text { tion." }\end{array}$

Comment: adequate allocation concealment

\begin{tabular}{ll}
\hline Blinding of participants & High risk Comment: participants and personnel not blinded \\
and personnel (perfor- &
\end{tabular}
mance bias)

\begin{tabular}{lll}
\hline $\begin{array}{l}\text { Blinding of outcome as- } \\
\text { sessment (detection bias) } \\
\text { Recurrence Free Survival }\end{array}$ & Unclear risk & Comment: Trial does not explicitly state who collected these data. \\
\hline $\begin{array}{l}\text { Blinding of outcome as- } \\
\text { sessment (detection bias) } \\
\text { QOL }\end{array}$ & High risk & Comment: participant-reported outcomes; participants not blinded \\
\hline $\begin{array}{l}\text { Blinding of outcome as- } \\
\text { sessment (detection bias) } \\
\text { Complications }\end{array}$ & High risk & $\begin{array}{l}\text { Quote from publication: "All complications were graded on the MSKCC modi- } \\
\text { fied Clavien grading scale. Complications data were collected prospectively by } \\
\text { unblinded MSKCC research study staff at the initial postoperative, 3-mo, and 6- } \\
\text { mo follow-up visits using the institution's standard reporting method for post- } \\
\text { operative complications." }\end{array}$
\end{tabular}

Comment: assessor unblinded 
Bochner 2015 (Continued)

Blinding of outcome as- Unclear risk Comment: not reported sessment (detection bias)

Transfusion Rates

Blinding of outcome as- Low risk Comment: unlikely to be affected by nonblinding
sessment (detection bias)
Hospital Stay

\begin{tabular}{lll}
\hline $\begin{array}{l}\text { Blinding of outcome as- } \\
\text { sessment (detection bias) }\end{array}$ & Low risk & $\begin{array}{l}\text { Quote from publication: "All pathologic specimens were reviewed blinded to } \\
\text { surgical technique." }\end{array}$
\end{tabular}

Positive Margin Rates

Comment: adequate blinding; additionally, regardless of blinding, low risk of detection bias

Incomplete outcome data Low risk
(attrition bias)
Complications/Transfu-
sion/Hospital Stay/Posi-
tive Margins

\begin{tabular}{|c|c|c|}
\hline $\begin{array}{l}\text { Incomplete outcome data } \\
\text { (attrition bias) }\end{array}$ & High risk & $\begin{array}{l}\text { Quote from publication: "Fifty-eight patients returned evaluable baseline sur- } \\
\text { veys and } 53 \text { returned follow-up surveys at } 3 \text { and } 6 \text { mo." }\end{array}$ \\
\hline
\end{tabular}

Comment: All randomised participants were included in the analysis for these outcomes.

QOL

Comment: In the RARC group, 60 participants were randomised, and 30 (50\%) participants returned surveys at 6 months. In the ORC group, 58 participants were randomised, and 22 (38\%) participants returned surveys at 6 months.

\begin{tabular}{lll}
\hline $\begin{array}{l}\text { Incomplete outcome data } \\
\text { (attrition bias) } \\
\text { Recurrence Free Survival }\end{array}$ & Low risk & Comment: All randomised participants were included in the analysis. \\
\hline $\begin{array}{l}\text { Selective reporting (re- } \\
\text { porting bias) }\end{array}$ & Low risk & $\begin{array}{l}\text { All predefined outcomes were reported for both groups in the time period sug- } \\
\text { gested. }\end{array}$ \\
\hline Other bias & Low risk & Comment: not detected \\
\hline
\end{tabular}

- Study design: randomised controlled 3-arm parallel-group, expertise-based, superiority trial
- Study date: March 2009 to July 2012
- Study setting: hospital setting -Guy's Hospital, London, UK
- Study authors estimated the RARC complication rate as $10 \%$ to $15 \%$ and the ORC complication rate
as $25 \%$ to $60 \%$. Therefore, the number needed in each arm ranges from 43 to 58 , so the $95 \% \mathrm{Cl}$ for the
estimated difference in rates is $16 \%$. Based on these considerations, researchers aimed to recruit 47
participants per arm. A 3-year interim analysis suggests no significant differences in primary outcomes
between arms, and, coupled with recruitment difficulties, the institutional research project steering
board recommended terminating the trial at that point.

\footnotetext{
Participants
}

\section{Adults undergoing radical cystectomy $(n=60)$ \\ Diagnostic criteria:}

- MIBC and high-risk NMIBC

\section{Inclusion criteria:}

- Participants between 18 and 80 years of age requiring RC for MIBC or high-risk NMIBC 
Khan 2016 (Continued)

\section{Exclusion criteria:}

- Unsuitable for laparoscopic radical cystectomy or robotic-assisted radical cystectomy due to severe cardiorespiratory comorbidities

- Extensive abdominopelvic surgery or radiation

\section{Demographic data: RARC vs ORC}

Mean age years $(\mathrm{SD})=68.6(6.8)$ vs $66.6(8.8)$

Male sex, $\mathrm{n}(\%)=17(85)$ vs $18(90)$

Body mass index, $\mathrm{kg} / \mathrm{m}^{2}$, mean $(\mathrm{SD})=27.5(4.2)$ vs 27.4 (3.9)

Cohort 1 = ORC with urinary diversion and PLND $(\mathrm{n}=20)$
Cohort 2 = RARC with extracorporeal urinary diversion and PLND $(\mathrm{n}=20)$
Cohort 3 = LRC with extracorporeal urinary diversion and PLND ( $\mathrm{n}=20)$
- All neobladders were fashioned using the Studer technique.
- Lymphadenectomy template: obturator, external/internal/common iliac, and presacral nodes
- Surgeon experience: This is an expertise-based study. At trial initiation, the ORC surgeon had per-
formed $>150$ ORCs and the RARC surgeon had performed 110 RARCs.
- Number of conversions from RARC to ORC: 0
- Pumber of participant cross-overs to ORC after randomising to RARC: 1 (equipment failure)
Primary end points
- Secondary end points
- Perioperative parameters (operative time, EBL, delay in bowel function, and LOS)
- Pathological outcomes (margin status and number of lymph nodes retrieved)
- 12 -month oncological outcomes
- QoL - study authors do not state in the methodology when they plan to assess

Funding sources

The research, including statistical support (Jennifer A. Summers and Janet L. Peacock), was supported by the National Institute for Health Research (NIHR) Biomedical Research Centre, based at Guy's and St. Thomas' NHS Foundation Trust and King's College London. Prokar Dasgupta and Kamran Ahmed acknowledge support from the NIHR Biomedical Research Centre, Medical Research Council Centre for Transplantation, King's Health Partners, Guy's and St. Thomas' Charity, School of Surgery, London Deanery, Royal College of Surgeons of England, Intuitive Surgical, The Urology Foundation, Olympus, EU-FP7, ProstateCancer UK, Technology Strategy Board, and The Vattikuti Foundation.

\begin{tabular}{lll}
\hline Declarations of interest & None & \\
\hline Notes & Language of publication: English \\
\hline Risk of bias & & \\
\hline Bias & Authors' judgement & Support for judgement \\
\hline $\begin{array}{l}\text { Random sequence genera- } \\
\text { tion (selection bias) }\end{array}$ & Low risk & $\begin{array}{l}\text { Quote from publication: "Randomisation was undertaken by the trial nurse } \\
\text { (J.W.) using identical sealed opaque envelopes, each containing a piece of pa- } \\
\text { per designating the surgical modality (ORC, LRC, or RARC). Simple randomisa- } \\
\text { tion was performed in two groups of 30. In each group, each modality was allo- } \\
\text { cated } 10 \text { envelopes. These were shuffled and then numbered 1-30. Patients re- } \\
\text { ceived the next envelope in numerical order." }\end{array}$
\end{tabular}

Comment: random sequence generation adequate 
Khan 2016 (Continued)

Allocation concealment Low risk (selection bias)
Quote from publication: "Envelopes were kept in a locked room, accessed only by the trial nurse to minimise opportunities for tampering, and they were opened by the patient in the presence of three members of the research team to ensure that no changes were made to allocation."

Comment: allocation concealment adequate

Blinding of participants High risk $\quad$ Comment: participants and personnel not blinded
and personnel (perfor-
mance bias)

Blinding of outcome as-

Unclear risk

sessment (detection bias)

Recurrence Free Survival
Comment: not reported

\begin{tabular}{lll}
\hline $\begin{array}{l}\text { Blinding of outcome as- } \\
\text { sessment (detection bias) } \\
\text { QOL }\end{array}$ & High risk & $\begin{array}{l}\text { Quote from publication: "This study was nonblinded because the different in- } \\
\text { cisions would be difficult to camouflage." }\end{array}$ \\
\hline $\begin{array}{l}\text { Blinding of outcome as- } \\
\text { sessment (detection bias) }\end{array}$ & High risk & $\begin{array}{l}\text { Quote from publication: "This study was nonblinded because the different in- } \\
\text { cisions would be difficult to camouflage." }\end{array}$
\end{tabular}

Complications

Comment: no outcome assessor blinding; study does not report the assessor

\begin{tabular}{ll}
\hline Blinding of outcome as- & Unclear risk $\quad$ Comment: not reported \\
sessment (detection bias) & \\
Transfusion Rates &
\end{tabular}

Blinding of outcome as-
$\begin{aligned} & \text { sessment (detection bias) } \\ & \text { Hospital Stay }\end{aligned}$

Blinding of outcome as- Low risk Comment: unlikely to be affected by nonblinding
sessment (detection bias)
Positive Margin Rates

Positive Margin Rates

Incomplete outcome data Low risk
(attrition bias)
Complications/Transfu-
sion/Hospital Stay/Posi-
tive Margins

Comment: All randomised participants were included in the analysis for these outcomes.

Incomplete outcome data High risk (attrition bias)

High risk

QOL

Quote from publication: "Overall, 53 patients completed the QoL questionnaire. One questionnaire was analysed per patient (average 8 mo postoperatively). Incomplete questionnaires were excluded."

Comment: In the RARC group, 20 participants were randomised, and 15 (75\%) participants returned surveys. In the ORC group, 20 participants were randomised, and 16 (80\%) participants returned surveys.

\begin{tabular}{|c|c|c|}
\hline $\begin{array}{l}\text { Incomplete outcome data } \\
\text { (attrition bias) } \\
\text { Recurrence Free Survival }\end{array}$ & Unclear risk & Comment: not reported \\
\hline $\begin{array}{l}\text { Selective reporting (re- } \\
\text { porting bias) }\end{array}$ & Low risk & $\begin{array}{l}\text { Comment: predefined outcomes reported for both groups in the time period } \\
\text { suggested }\end{array}$ \\
\hline
\end{tabular}




- Study design: randomised noninferiority single-centre study
- Study period: April 2008 and January 2009
- Study setting: hospital based -University of North Carolina at Chapel Hill, Chapel Hill, North Carolina,
USA
- LN yield was selected as the primary end point used for power analysis
- The null hypothesis was that mean LN yield for open cystectomy was higher than that for robotic cys-
tectomy. A sample size of 20 participants per arm was calculated to provide $80 \%$ power and a 0.05
type 1 error rate to demonstrate the noninferiority of open to robotic cystectomy with respect to $\mathrm{LN}$
count based on a critical difference of 4 LNs. The $90 \%$ one-sided Cl of this difference is reported be-
cause of the $5 \%$ significance used for the sample size calculation. If the upper level of this Cl is $>4$, the
null hypothesis cannot be rejected and noninferiority has not been achieved.

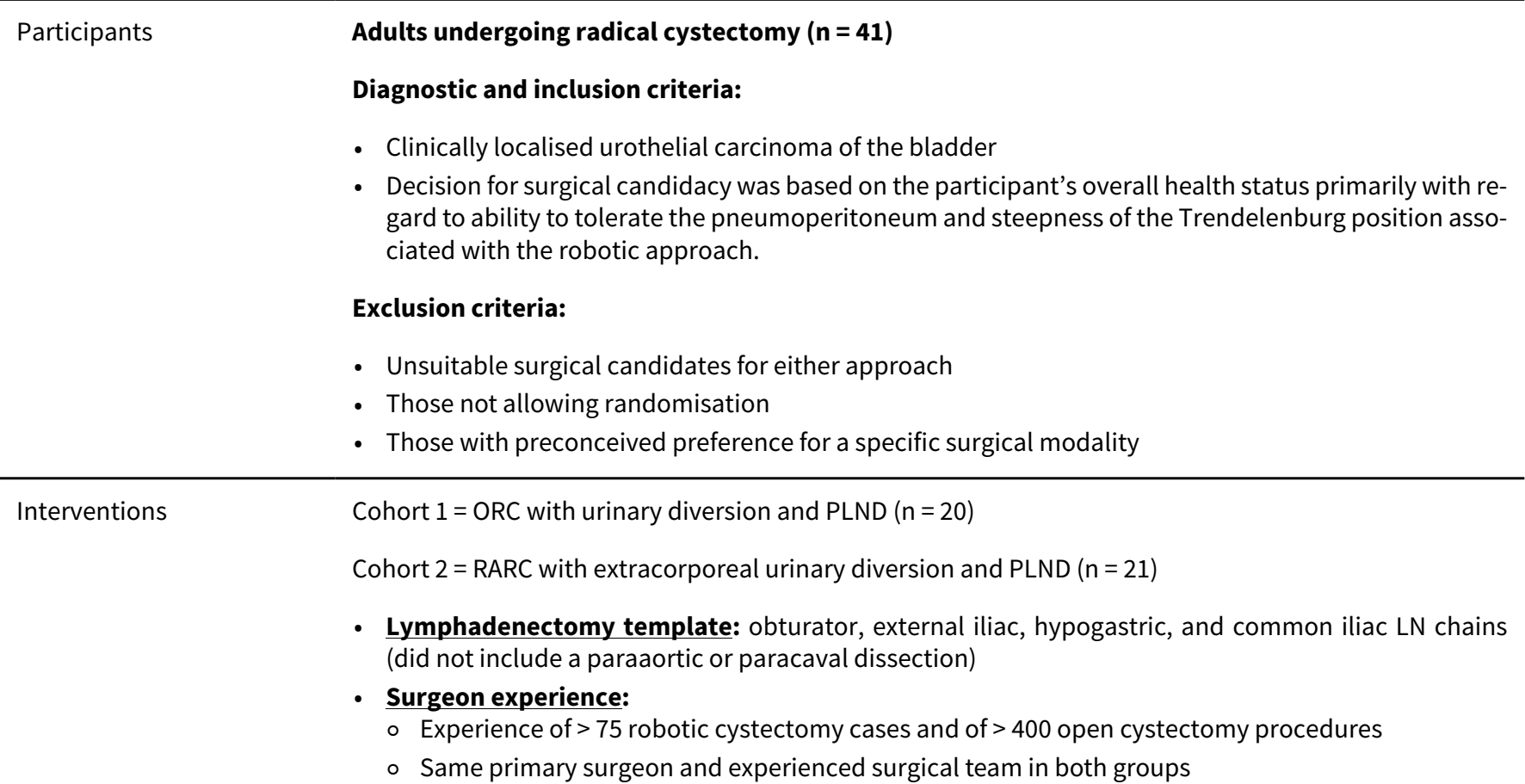

\section{Demographic data: RARC vs ORC}

Mean age years $=67.4$ vs 69.2

Male:Female $=14: 7$ vs $17: 3$

Body mass index, $\mathrm{kg} / \mathrm{m}^{2}$, mean $=27.5$ vs 28.4

\begin{tabular}{ll}
\hline Outcomes & EBL \\
- Operative time \\
- Complications \\
- Recovery of bowel function \\
- Length of stay when assessed \\
- Margin status \\
- Lymph node count \\
- Time to adjuvant chemotherapy
\end{tabular}


Nix 2010 (Continued)

Declarations of interest None

Notes Language of publication: English

\section{Risk of bias}

\begin{tabular}{lll}
\hline Bias & Authors' judgement & Support for judgement \\
\hline $\begin{array}{l}\text { Random sequence genera- } \\
\text { tion (selection bias) }\end{array}$ & Low risk & $\begin{array}{l}\text { Quote from publication: "The randomizations schema was performed with } \\
\text { five sequential patients undergoing an approach before alternating surgical } \\
\text { modality." }\end{array}$
\end{tabular}

Comment: random sequence generation adequate

$\begin{array}{ll}\begin{array}{l}\text { Allocation concealment } \\ \text { (selection bias) }\end{array} & \text { Quote from publication: "The randomization schema was performed with } \\ & \text { five sequential patients undergoing an approach before alternating surgical } \\ \text { modality. This scheme was chosen, as opposed to randomizing each sequen- } & \text { tial patient, for the purpose of resident education. We believed that alternat- } \\ \text { ing each sequential surgery as to approach would make it significantly more } & \text { difficult for residents to progress through their knowledge and acquisition of } \\ \text { proficiency in each of the individual procedures." }\end{array}$

Comment: allocation concealment inadequate

Blinding of participants High risk Comment: participants and personnel not blinded
and personnel (perfor-
mance bias)

\begin{tabular}{lll}
\hline $\begin{array}{l}\text { Blinding of outcome as- } \\
\text { sessment (detection bias) } \\
\text { Recurrence Free Survival }\end{array}$ & Unclear risk & Comment: not reported \\
\hline $\begin{array}{l}\text { Blinding of outcome as- } \\
\text { sessment (detection bias) } \\
\text { QOL }\end{array}$ & Unclear risk & Comment: not applicable as not reported \\
\hline $\begin{array}{l}\text { Blinding of outcome as- } \\
\text { sessment (detection bias) } \\
\text { Complications }\end{array}$ & Unclear risk & $\begin{array}{l}\text { Comment: no report on who collected outcomes and if they were blinded to } \\
\text { the procedure }\end{array}$ \\
\hline
\end{tabular}

\begin{tabular}{|c|c|c|}
\hline $\begin{array}{l}\text { Blinding of outcome as- } \\
\text { sessment (detection bias) } \\
\text { Transfusion Rates }\end{array}$ & Unclear risk & Comment: not applicable as not reported \\
\hline
\end{tabular}

Blinding of outcome as- Low risk Comment: unlikely to be affected by nonblinding
sessment (detection bias)
Hospital Stay

\begin{tabular}{|c|c|c|}
\hline $\begin{array}{l}\text { Blinding of outcome as- } \\
\text { sessment (detection bias) } \\
\text { Positive Margin Rates }\end{array}$ & Low risk & Comment: unlikely to be affected by nonblinding \\
\hline
\end{tabular}

$\begin{aligned} & \text { Incomplete outcome data Low risk } \\ & \text { (attrition bias) }\end{aligned}$
Complications/Transfu-
sion/Hospital Stay/Posi-
tive Margins


Nix 2010 (Continued)
Incomplete outcome data
Unclear risk
Comment: not applicable as not reported (attrition bias)

QOL

$\begin{array}{lll}\begin{array}{l}\text { Incomplete outcome data } \\ \text { (attrition bias) }\end{array} & \text { Unclear risk } & \text { Comment: not reported } \\ \text { Recurrence Free Survival } & & \\ \begin{array}{l}\text { Selective reporting (re- } \\ \text { porting bias) }\end{array} & \text { Unclear risk } & \text { No protocol published }\end{array}$

Other bias Low risk None

Parekh 2013

$\begin{array}{ll}\text { Methods } & \text { Study design: pilot prospective RCT } \\ & \text { - Study date: July } 2009 \text { to June } 2011 \\ & \text { - Study setting: single-institution study-University of Texas Health Sciences Center at San Antonio, San } \\ & \text { Antonio, Texas, USA } \\ \text { - } & \text { Pilot trial to establish } \\ & \circ \text { Feasibility and safety of the robotic approach } \\ & \circ \text { Preliminary data to determine statistical analyses and outcome measures for a phase } 3 \text { multi-in- } \\ & \text { stitutional clinical trial }\end{array}$

Participants

Adults undergoing radical cystectomy $(n=40)$

\section{Diagnostic criteria:}

- Biopsy-proven bladder cancer of clinical stage T1-T3, N0, M0

\section{Inclusion criteria:}

- Candidates for an open or robotic approach at the discretion of the treating surgeon

\section{Exclusion criteria:}

- Inability to give informed consent

- Multiple prior abdominal and pelvic open surgical procedures that would preclude a safe robotic approach

- Morbid obesity that would preclude the robotic approach

- Clinical T4 bladder cancer

- Clinical lymph node-positive bladder cancer with grossly enlarged pelvic or retroperitoneal lymph nodes

- Any preexisting condition that precludes safe initiation or maintenance of pneumoperitoneum for a prolonged period

- Age younger than 30 or older than 90 years

- Pregnancy

\section{Demographic data: RARC vs ORC}

Median age years $(\mathrm{IQR})=69.5(62.3$ to 74$)$ vs $64.5(59.8$ to 72.3$)$

Male:Female $=18: 2$ vs $16: 4$

Body mass index, $\mathrm{kg} / \mathrm{m}^{2}$, median (IQR) $=27.6$ (24.2 to 29.9 ) vs 28.3 (26.1 to 32.3 ) 
Parekh 2013 (Continued)

Cohort 2 = RARC with open urinary diversion and PLND $(n=20)$

- The type of urinary diversion was performed at the discretion of the surgeon. The study does not explicitly state if the urinary diversion was performed with an extracorporeal or intracorporeal approach.

- Lymphadenectomy template: Lymph node dissection for both groups was performed superiorly to the level of the ureteral crossing of the common iliac vessels, including the internal iliac artery and the obturator fossa, and laterally to the genitofemoral nerve, including the tissue overlying the psoas muscle.

- Surgeon experience: The primary faculty involved in the study had an independent experience of more than 100 ORCs and had performed approximately 50 RARCs.

- Number of conversions from RARC to ORC: 0

- Number of participant cross-overs to ORC after randomising to RARC: 0

\begin{tabular}{ll}
\hline Outcomes & Establish the feasibility of randomising participants \\
- & Obtain preliminary data on oncological efficacy, perioperative outcomes, and $\mathrm{HRQ}$ oL outcomes \\
- & Evaluate HRQoL using the $\mathrm{FACT}-\mathrm{VCl}$ questionnaire preoperatively, and then at $3,6,9$, and 12 months \\
& postoperatively
\end{tabular}

\begin{tabular}{ll}
\hline Funding sources & Not reported in the study \\
\hline Declarations of interest & None \\
\hline
\end{tabular}

Notes

\section{Risk of bias}

Bias Authors' judgement Support for judgement

Random sequence genera- Low risk Quote from publication: "Patients who met the inclusion criteria were rantion (selection bias) domized to open or robotic radical cystectomy at their preoperative clinic visit using a computerized randomization program (www.randomization.com) (see figure). This program generated a list of surgical slots numbered 1 through 60 , and randomly assigned open or robotic assisted cystectomy to each slot (30 slots for each procedure)."

Comment: random sequence generation adequate

\begin{tabular}{ll}
\hline $\begin{array}{l}\text { Allocation concealment } \\
\text { (selection bias) }\end{array}$ & Quw risk \\
& $\begin{array}{l}\text { Quote from publication: "Each assignment was placed in a sealed envelope } \\
\text { with the corresponding slot number written on the outside. At the time of con- } \\
\text { sent the lowest numbered envelope remaining was opened and the patient } \\
\text { was assigned to the surgical procedure listed on the piece of paper inside the } \\
\text { envelope." }\end{array}$
\end{tabular}

Comment: allocation concealment adequate

Blinding of participants High risk Comment: participants and personnel not blinded
and personnel (perfor-
mance bias)

Blinding of outcome as-
sessment (detection bias)

Unclear risk

Comment: not reported

Recurrence Free Survival

Blinding of outcome as- High risk sessment (detection bias)

$\mathrm{QOL}$

Quote from publication: "The surgical team and the patient were then made aware of the type of surgery." 
Parekh 2013 (Continued)

Comment: Participants were aware of the approach they had; hence there would have been an expectation bias when they completed their QoL questionnaires. Participant-reported outcomes. Participants not blinded.

\begin{tabular}{|c|c|c|}
\hline $\begin{array}{l}\text { Blinding of outcome as- } \\
\text { sessment (detection bias) } \\
\text { Complications }\end{array}$ & Unclear risk & $\begin{array}{l}\text { Comment: The study does not state who the outcome assessor was; it is un- } \\
\text { clear if the assessor was blinded. }\end{array}$ \\
\hline
\end{tabular}

Blinding of outcome as- Low risk Comment: unlikely to be affected by nonblinding
sessment (detection bias)
Transfusion Rates

Transfusion Rates

Blinding of outcome as- Low risk Comment: unlikely to be affected by nonblinding
sessment (detection bias)
Hospital Stay

Blinding of outcome as-
$\begin{aligned} & \text { sessment (detection bias) } \\ & \text { Positive Margin Rates }\end{aligned}$

Incomplete outcome data Low risk

Comment: Most randomised participants were included in the analysis for

(attrition bias) these outcomes.

Complications/Transfu-

sion/Hospital Stay/Posi-

tive Margins

Incomplete outcome data High risk

(attrition bias)

Quote from second publication: "The study is limited by the response rate to

QOL the questionnaires, with sampling at only $50 \%$ for some time periods, which only underscores the difficulty of obtaining prospective data with regard to HRQoL."

Comment: Reported in the second publication. In the RARC group, 20 participants were randomised, and $12(60 \%)$ participants returned surveys at 12 months. In the ORC group, 20 participants were randomised, and 13 (65\%) participants returned surveys at 12 months.

\begin{tabular}{lll}
\hline $\begin{array}{l}\text { Incomplete outcome data } \\
\text { (attrition bias) } \\
\text { Recurrence Free Survival }\end{array}$ & Unclear risk & Comment: not reported \\
\hline $\begin{array}{l}\text { Selective reporting (re- } \\
\text { porting bias) }\end{array}$ & Low risk & All predefined outcomes measured \\
\hline Other bias & Low risk & None \\
\hline
\end{tabular}

\title{
Parekh 2018
}

$\begin{array}{ll}\text { Methods } & \text { Study design: multicentre, open-label, randomised, phase 3, noninferiority trial } \\ \text { - Study setting: } 15 \text { medical centres in the USA }\end{array}$

\section{Participants}

\author{
Adults undergoing radical cystectomy \\ Diagnostic criteria and inclusion criteria: \\ - Biopsy-proven clinical stage T1-T4, N0-N1, M0 bladder cancer or refractory carcinoma in situ \\ - Age of 18 years or older
}


Parekh 2018 (Continued)

\section{Exclusion criteria:}

- Open abdominal or pelvic surgery or any preexisting health condition that would preclude safe initiation or maintenance of pneumoperitoneum

- Pregnant women

Interventions

Intention-to-treat analysis

Cohort $1=$ ORC with urinary diversion and PLND $(n=159)$

Cohort $2=$ RARC with open urinary diversion and PLND $(n=153)$

- All urinary diversions were extracorporeal.

- Lymphadenectomy template: Extent of pelvic lymph node dissection (standard or extended) was based on institutional preference.

- Surgeon experience: Surgeons performing RARC and/or ORC must have performed $\geq 10$ procedures each over the 1 year before approval as a study site.

- Use of chemotherapy was based on institutional preference.

Outcomes

\section{Primary outcome}

- 2-year progression-free survival

Quote from publication: "Disease progression was determined on the basis of radiographical or pathological evidence of disease, or death from disease according to Response Evaluation Criteria in Solid Tumours criteria version 1.1."

\section{Secondary outcomes}

- Blood loss

- Blood transfusion rates

- Surgical margin status

- Number of lymph nodes

- Operating time

- Length of hospital stay

- 90-day surgical complications

- 3- and 6-month health-related QoL outcomes

- Quote from publication: "Change in baseline serum haemoglobin, creatinine, and albumin concentrations at 4-6 weeks, and at 3, 6, 12, 24, and 36 months, intraoperative fluid requirements, and analgesic requirements."

\section{Exploratory end points}

- Overall survival

- Quote from publication: "Activities and instrumental activities of daily living scores, hand grip strength, and timed up and go walking test outcomes, assessed at 4-6 weeks, 3 months, and 6 months." work. MEW reports grants from the National Institutes of Health $(\mathrm{NIH})$ during the study, and outside the submitted work. AZW reports grants from the University of Michigan during the study. BRK reports grants from the National Cancer Institute during the study; and grants from Photocure, Roche-Genentech, Genomic Health, Myriad Genetics, Spectrum, and FKD Therapies, outside the submitted work. MT reports grants from the NIH during the study. TLK reports grants from the NIH during the study. DAB reports grants from the $\mathrm{NIH}$, during the study; and personal fees from AstraZeneca, Tolmar Pharmaceuticals, and Janssen, outside the submitted work. ASK reports advisory board fees from Profound, SanofiAventis, and Janssen, outside the submitted work. CJW reports grants from Myriad Genetics and personal fees from Abbott Molecular, outside the submitted work. MSC has served on advisory boards for 
Parekh 2018 (Continued)

Astellas Pharma US, MDxHealth, Janssen, Bayer Healthcare, CicloMed, Abbott Laboratories, Tolmar Pharmaceuticals, Genomic Health, Altor Bioscience, Photocure, and Takeda Pharmaceutical; and reports consultancy fees from Myovant Sciences, TesoRx Pharma, and Pacific Edge Diagnostics. All other authors declare no competing interests."

Notes Language of publication: English

\section{Risk of bias}

\begin{tabular}{|c|c|c|}
\hline Bias & Authors' judgement & Support for judgement \\
\hline $\begin{array}{l}\text { Random sequence genera- } \\
\text { tion (selection bias) }\end{array}$ & Low risk & $\begin{array}{l}\text { Quote from study: "By use of a dynamic balancing algorithm, patients were } \\
\text { centrally randomly assigned ( } 1: 1 \text { ) via a web-based system, to receive open cys- } \\
\text { tectomy or robotic cystectomy. Using each institution as a block, the dynam- } \\
\text { ic allocation procedure allocated an approximately equal number of patients } \\
\text { to treatment groups to minimise imbalance between groups, stratified by type } \\
\text { of urinary diversion (incontinent or continent), clinical T stage (carcinoma in } \\
\text { situ, T1-T2, or T3-T4), and Eastern Cooperative Oncology Group (ECOG) per- } \\
\text { formance status ( } 0-1 \text {, or }=2 \text { ). On accrual a hierarchical decision-rule was ap- } \\
\text { plied, and the allocation was deterministic if certain predefined limits were ex- } \\
\text { ceeded, and random otherwise." }\end{array}$ \\
\hline
\end{tabular}

\begin{tabular}{ll}
\hline $\begin{array}{l}\text { Allocation concealment } \\
\text { (selection bias) }\end{array}$ & Quote from study: "By use of a dynamic balancing algorithm, patients were \\
& centrally randomly assigned (1:1) via a web-based system, to receive open cys- \\
& tectomy or robotic cystectomy. Using each institution as a block, the dynam- \\
& ic allocation procedure allocated an approximately equal number of patients \\
& to treatment groups to minimise imbalance between groups, stratified by type \\
& of urinary diversion (incontinent or continent), clinical T stage (carcinoma in \\
situ, T1-T2, or T3-T4), and Eastern Cooperative Oncology Group (ECOG) per- \\
formance status (0-1, or $=2)$. On accrual a hierarchical decision-rule was ap- \\
plied, and the allocation was deterministic if certain predefined limits were ex- \\
ceeded, and random otherwise."
\end{tabular}

\begin{tabular}{|c|c|c|}
\hline $\begin{array}{l}\text { Blinding of participants } \\
\text { and personnel (perfor- } \\
\text { mance bias) }\end{array}$ & High risk & $\begin{array}{l}\text { Comment: in view of the nature of the study, unlikely to be blinded } \\
\text { Quote from study: "Treatment allocation was only masked from pathologists, } \\
\text { who analysed the cystectomy specimens." }\end{array}$ \\
\hline
\end{tabular}

\begin{tabular}{lll}
\hline $\begin{array}{l}\text { Blinding of outcome as- } \\
\text { sessment (detection bias) } \\
\text { Recurrence Free Survival }\end{array}$ & High risk & $\begin{array}{l}\text { Quote from study: "Treatment allocation was only masked from pathologists, } \\
\text { who analysed the cystectomy specimens." }\end{array}$ \\
\hline $\begin{array}{l}\text { Blinding of outcome as- } \\
\text { sessment (detection bias) } \\
\mathrm{OOL}\end{array}$ & High risk & $\begin{array}{l}\text { Quote from study: "Treatment allocation was only masked from pathologists, } \\
\text { who analysed the cystectomy specimens." }\end{array}$ \\
\hline
\end{tabular}
QOL

Blinding of outcome as-
sessment (detection bias)
Quote from study: "Treatment allocation was only masked from pathologists, who analysed the cystectomy specimens." Complications

\begin{tabular}{lll}
\hline $\begin{array}{l}\text { Blinding of outcome as- } \\
\text { sessment (detection bias) } \\
\text { Transfusion Rates }\end{array}$ & Low risk & Unlikely to be affected by nonblinding \\
\hline $\begin{array}{l}\text { Blinding of outcome as- } \\
\text { sessment (detection bias) } \\
\text { Hospital Stay }\end{array}$ & Low risk & Unlikely to be affected by nonblinding \\
\hline
\end{tabular}


Parekh 2018 (Continued)

Blinding of outcome as- Low risk sessment (detection bias)

Positive Margin Rates
Quote from study: "Treatment allocation was only masked from pathologists, who analysed the cystectomy specimens."

Comment: Unlikely to be affected by nonblinding
Incomplete outcome data Low risk

(attrition bias)

Complications/Transfu-

sion/Hospital Stay/Posi-

tive Margins
Comment: Most randomised participants were included in analysis for these outcomes.
Incomplete outcome data High risk (attrition bias)

QOL
Comment: At 6 months, QoL data were available for only 198 participants (63.4\%).

Incomplete outcome data Unclear risk (attrition bias)

Recurrence Free Survival

Quote from study: "Between July 1, 2011, and Nov 18, 2014, 350 patients were randomly assigned to treatment: 176 to the robotic cystectomy group and 174 to the open cystectomy group. Of the 176 patients who were randomly assigned to receive robotic cystectomy, $17(10 \%)$ patients did not have surgery and nine $(5 \%)$ patients had a different surgery to that they were assigned. Of the 174 patients assigned to receive open cystectomy, $21(12 \%)$ patients did not have surgery and one (1\%) patient had robotic cystectomy instead of open cystectomy."

Selective reporting (re- Low risk Comment: all predefined outcomes measured
porting bias)

Other bias

Low risk

Comment: nil

CI: confidence interval; EBL: estimated blood loss; FACT-VCI: Functional Assessment of Cancer Therapy -Vanderbilt Cystectomy Index; HRQoL: health-related quality of life; IQR: interquartile range; ITT: intention-to-treat; LN: lymph node; LOS: length of (hospital) stay; LRC: laparoscopic radical cystectomy; MIBC: muscle-invasive bladder cancer; NMIBC: non-muscle-invasive bladder cancer; ORC: open radical cystectomy; PLND: pelvic lymph node dissection; QoL: quality of life; RARC: robotic-assisted radical cystectomy; RC: radical cystectomy; $\mathrm{RCT}$ : randomised controlled clinical trial; SD: standard deviation.

Characteristics of excluded studies [ordered by study ID]

\begin{tabular}{ll}
\hline Study & Reason for exclusion \\
\hline Anderson 2013 & $\begin{array}{l}\text { Not a randomised controlled study. In this study, benign ureteroenteric anastomotic stricture rates } \\
\text { of open and robot assisted laparoscopic radical cystectomy were compared using a prospectively } \\
\text { maintained database. }\end{array}$ \\
\hline Atmaca 2015 & $\begin{array}{l}\text { Not a randomised controlled study. Retrospective comparison of open vs totally intracorporeal ro- } \\
\text { botic-assisted radical cystectomy, bilateral extended pelvic lymph node dissection, and Studer uri- } \\
\text { nary diversion. Researchers evaluated operative and postoperative parameters, pathological para- } \\
\text { meters, complications, and functional outcomes. }\end{array}$ \\
\hline Bak 2016 & $\begin{array}{l}\text { Although not clearly specified, this appears to be a nonrandomised retrospective observational } \\
\text { study. }\end{array}$ \\
\hline Borza 2017 & $\begin{array}{l}\text { Not a randomised controlled study. Participants were identified from International Classification of } \\
\text { Diseases 9th edition codes and administrative claims from a large, national US health insurer. This } \\
\text { study compared readmission rates for ORC and RARC. }\end{array}$ \\
\hline
\end{tabular}




\begin{tabular}{ll}
\hline Study & Reason for exclusion \\
\hline Cusano 2016 & $\begin{array}{l}\text { Not a randomised controlled study. Retrospective comparison of preliminary oncological out- } \\
\text { comes for ORC and RARC. }\end{array}$ \\
\hline Galich 2006 & $\begin{array}{l}\text { Not a randomised controlled study. This study compared early perioperative outcomes following } \\
\text { radical cystectomy by the robotic method vs the conventional open method using a prospectively } \\
\text { maintained database. }\end{array}$ \\
\hline Gandaglia 2016 & $\begin{array}{l}\text { Not a randomised controlled study. Retrospective comparison of perioperative and oncological } \\
\text { outcomes of open (ORC) and robotic-assisted radical cystectomy (RARC) between } 2 \text { large-volume } \\
\text { European centres. }\end{array}$ \\
\hline
\end{tabular}

Ginot $2016 \quad$ Not a randomised controlled study. Comparison of robotic-assisted cystectomy vs open cystectomy, with urinary diversion by bladder substitution.

\section{Gondo $2012 \quad$ Not a randomised controlled study. This study compared early perioperative outcomes following radical cystectomy by the robotic method vs the conventional open method using a prospectively maintained database in a Japanese population.}

$\begin{array}{ll}\text { Khan } 2012 & \text { Not a randomised controlled study. This prospective study compared perioperative outcomes of } \\ \text { ORC, RARC, and LRC. }\end{array}$

\begin{tabular}{ll}
\hline Koupparis 2015 & Not a randomised controlled study. This study compared the impact of ERAS between prospective \\
RARC data and retrospectively maintained ORC data.
\end{tabular}

\begin{tabular}{ll}
\hline Lee 2011 & $\begin{array}{l}\text { Not a randomised controlled study. This prospective comparative study compared the economic } \\
\text { burden of ORC vS RARC. }\end{array}$ \\
\hline Li 2016 & $\begin{array}{l}\text { Not a randomised controlled study. This retrospective study compared health-related quality of life } \\
\text { (HRQOL) and short-term convalescence among bladder cancer patients who underwent ORC and } \\
\text { RARC. }\end{array}$ \\
\hline
\end{tabular}

\begin{tabular}{ll}
\hline Martin 2011 & $\begin{array}{l}\text { Not a randomised controlled study. This prospective comparative study performed cost analysis of } \\
\text { ORC and RARC. }\end{array}$ \\
\hline Matulewicz 2016 & $\begin{array}{l}\text { Not a randomised controlled study. Researchers used the National Cancer Data Base to compare } \\
\text { oncological quality indicators between open and robotic-assisted radical cystectomy. }\end{array}$
\end{tabular}

\begin{tabular}{ll}
\hline Musch 2014 & Not a randomised controlled study. This prospective comparative study compared early postoper- \\
& ative morbidity of ORC and RARC.
\end{tabular}

\begin{tabular}{ll}
\hline Nepple 2013 & $\begin{array}{l}\text { Not a randomised controlled study. This retrospective non-matched study compared pathology, } \\
\text { recurrence, and survival between ORC and RARC. }\end{array}$ \\
\hline Ng 2010 & $\begin{array}{l}\text { Not a randomised controlled study. This prospective study compared complications between ORC } \\
\text { and RARC. }\end{array}$ \\
\hline Nguyen 2015 & $\begin{array}{l}\text { Not a randomised controlled study. This retrospective study compared RFS and recurrence pat- } \\
\text { terns between ORC and RARC. }\end{array}$ \\
\hline Rhee 2006 & $\begin{array}{l}\text { Not a randomised controlled study. This prospective comparative study compared estimated } \\
\text { blood loss (EBL), transfusion requirements, operative duration, hospital stay, and body mass index } \\
\text { (BMI) between ORC and RARC. }\end{array}$ \\
\hline Satkunasivam 2016 & $\begin{array}{l}\text { Not a randomised controlled study. This retrospective study compared urodynamic features of in- } \\
\text { tracorporeal orthotopic neobladder and bladder cancer-specific and general health-related quality } \\
\text { of life between RARC and ORC. }\end{array}$
\end{tabular}




\begin{tabular}{ll}
\hline Study & Reason for exclusion \\
\hline Sharma 2017 & $\begin{array}{l}\text { Not a randomised controlled study. This retrospective study compared pathological and postoper- } \\
\text { ative outcomes of RARC vs open radical cystectomy (ORC) with high-risk disease (pT3/T4). }\end{array}$ \\
\hline Styn 2012 & $\begin{array}{l}\text { Not a randomised controlled study. This matched-pair analysis compared ORC and RARC. Re- } \\
\text { searchers match-paired age, sex, urinary diversion, and clinical stage, and they compared perioper- } \\
\text { ative complications and pathological outcomes. }\end{array}$ \\
\hline Tan 2016 & $\begin{array}{l}\text { Not a randomised controlled study. Investigators compared early oncological outcomes and can- } \\
\text { cer recurrence sites among patients undergoing ORC and RARC with intracorporeal urinary diver- } \\
\text { sion (iRARC). }\end{array}$ \\
\hline Wang 2008 & $\begin{array}{l}\text { Not a randomised controlled study. This prospective study compared estimated blood loss (EBL), } \\
\text { transfusion requirement, operative duration, time to resumption of regular diet, hospital stay, } \\
\text { complication rates, and pathological outcomes between ORC and RARC. }\end{array}$ \\
\hline Winters 2016 & $\begin{array}{l}\text { Not a randomised controlled study. This study compared perioperative surgical outcomes among } \\
\text { elderly patients. }\end{array}$ \\
\hline
\end{tabular}

BMI: body mass index; EBL: estimated blood loss; ERAS: Enhanced recovery after syrgery; HRQoL: health-related quality of life; iRARC: intracorporeal urinary diversion; LRC: laparoscopic radical cystectomy; ORC: open radical cystectomy; RARC: robotic-assisted radical cystectomy; RFS: Recurrence-free survival.

\section{Characteristics of ongoing studies [ordered by study ID]}

Kelly, Catto 2017

Trial name or title IROC (Trial to Compare Robotically Assisted Radical Cystectomy With Open Radical Cystectomy)

\begin{tabular}{ll}
\hline Methods & Phase III multicentre randomised controlled trial \\
\hline Participants & Patients with non-muscle-invasive bladder cancer (NMIBC) or muscle-invasive bladder cancer \\
& (MIBC) who had selected radical cystectomy for treatment of bladder cancer; planned accrual of \\
& 320 participants
\end{tabular}

\begin{tabular}{ll}
\hline Interventions & $\begin{array}{l}\text { Robotically assisted radical cystectomy and intracorporeal urinary diversion vs open radical cys- } \\
\text { tectomy }\end{array}$
\end{tabular}

\begin{tabular}{ll}
\hline Outcomes & Primary outcome measures: \\
& D Days at home within 90 days of surgery \\
& Secondary outcome measures: \\
& $\cdot$ by WHODAS version 2.0 \\
& Q Quality of life measured by EQ-5D-5L Health Questionnaire and EORTC QLQ-C30 version 3 \\
\hline Starting date & 01/03/2017 (estimated study completion date: 15 February 2020) \\
\hline Contact information & Chris Brew-Graves; 0207679 9280; situ.iroc@ucl.ac.uk \\
\hline Notes & ClinicalTrials.gov identifier (NCT number): NCT03049410 \\
\hline
\end{tabular}

EORTC QLQ-C30: European Organisation for Research and Treatment of Cancer Quality of Life Questionnaire Core 30; EQ-5D-5L: EuroQol 5 Domains 5 Levels; MIBC: muscle-invasive bladder cancer; NMIBC: non-muscle-invasive bladder cancer; WHODAS: World Health Organization Disability Assessment Schedule. 


\section{DATA AND ANALYSES}

Comparison 1. Robotic-assisted laparoscopic versus open radical cystectomy

\begin{tabular}{|c|c|c|c|c|}
\hline Outcome or subgroup title & No. of studies & $\begin{array}{l}\text { No. of partici- } \\
\text { pants }\end{array}$ & Statistical method & Effect size \\
\hline 1 Recurrence-free survival & 2 & 430 & Hazard Ratio (Random, 95\% Cl) & $1.05[0.77,1.43]$ \\
\hline $\begin{array}{l}2 \text { Major postoperative compli- } \\
\text { cation rates (Clavien } 3 \text { to } 5 \text { ) }\end{array}$ & 5 & 541 & Risk Ratio (M-H, Random, 95\% Cl) & $1.06[0.76,1.48]$ \\
\hline $\begin{array}{l}3 \text { Minor postoperative compli- } \\
\text { cation rates (Clavien } 1 \text { and } 2 \text { ) }\end{array}$ & 4 & 423 & Risk Ratio (M-H, Random, 95\% Cl) & $0.82[0.58,1.17]$ \\
\hline 4 Transfusion rate & 2 & 326 & Risk Ratio (M-H, Random, 95\% Cl) & $0.58[0.43,0.80]$ \\
\hline 5 Hospital stay & 5 & 541 & $\begin{array}{l}\text { Mean Difference (IV, Random, 95\% } \\
\mathrm{CI})\end{array}$ & $-0.67[-1.22,-0.12]$ \\
\hline 6 Quality of life & 3 & 270 & $\begin{array}{l}\text { Std. Mean Difference (IV, Random, } \\
95 \% \mathrm{CI} \text { ) }\end{array}$ & $-0.08[-0.32,0.16]$ \\
\hline 7 Positive margin & 5 & 541 & Risk Ratio (M-H, Random, 95\% Cl) & $1.16[0.56,2.40]$ \\
\hline
\end{tabular}

Analysis 1.1. Comparison 1 Robotic-assisted laparoscopic versus open radical cystectomy, Outcome 1 Recurrence-free survival.

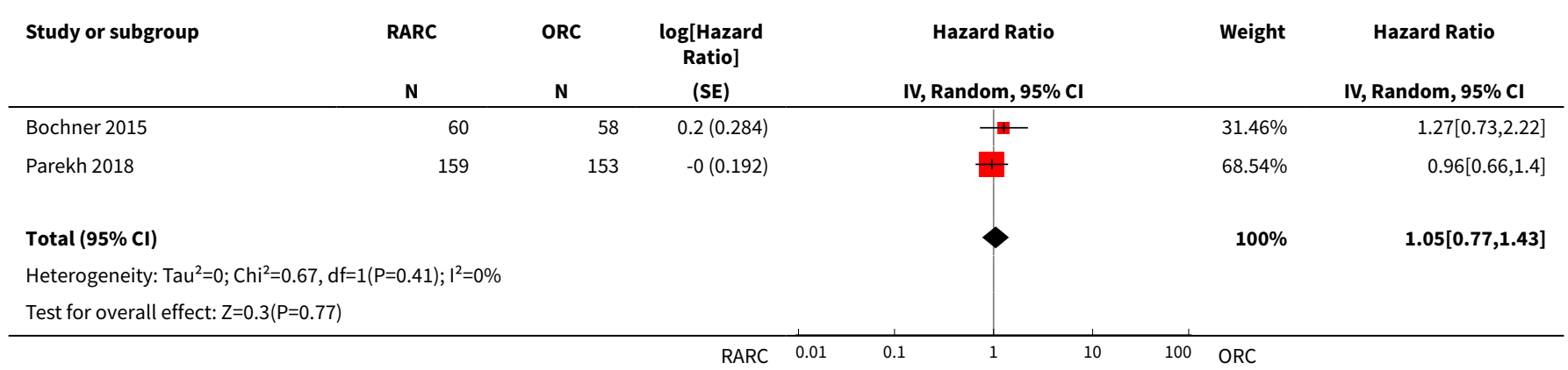

Analysis 1.2. Comparison 1 Robotic-assisted laparoscopic versus open radical cystectomy, Outcome 2 Major postoperative complication rates (Clavien 3 to 5).

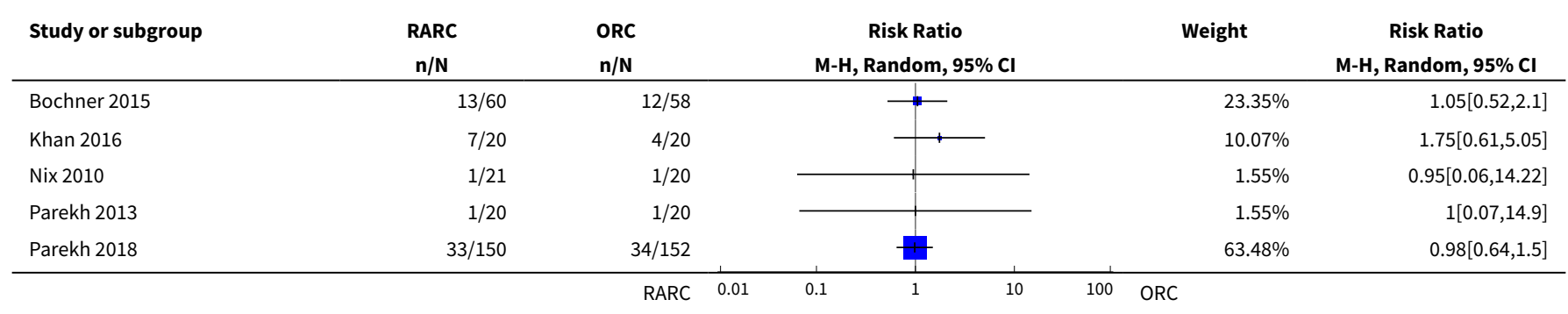




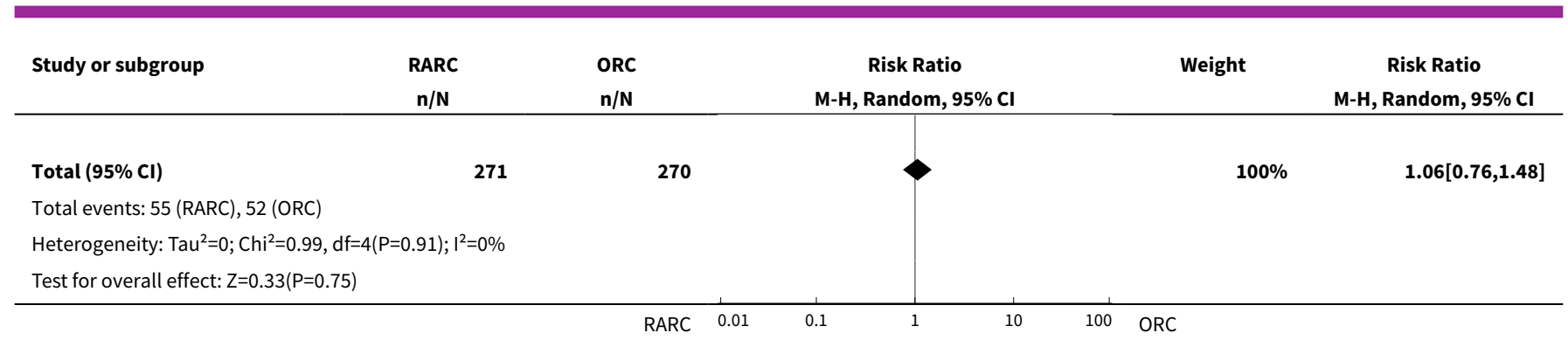

Analysis 1.3. Comparison 1 Robotic-assisted laparoscopic versus open radical cystectomy, Outcome 3 Minor postoperative complication rates (Clavien 1 and 2).

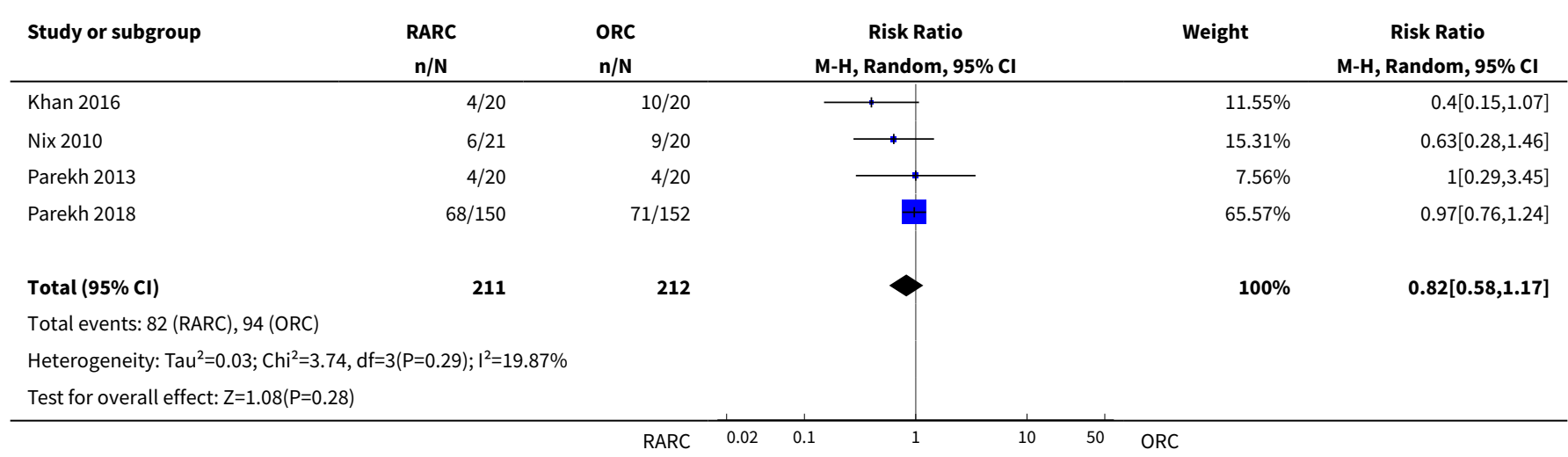

Analysis 1.4. Comparison 1 Robotic-assisted laparoscopic versus open radical cystectomy, Outcome 4 Transfusion rate.

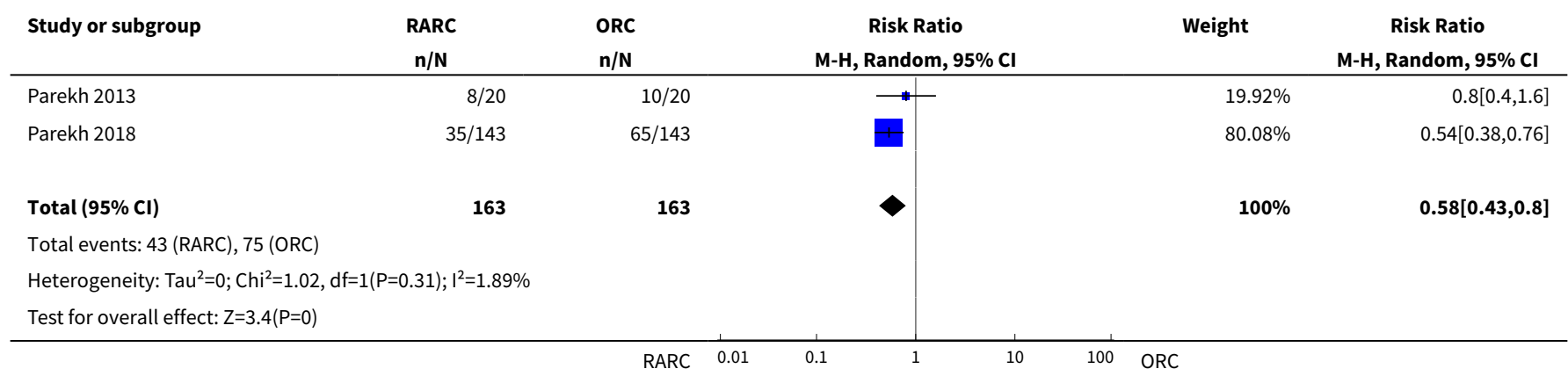

Analysis 1.5. Comparison 1 Robotic-assisted laparoscopic versus open radical cystectomy, Outcome 5 Hospital stay.

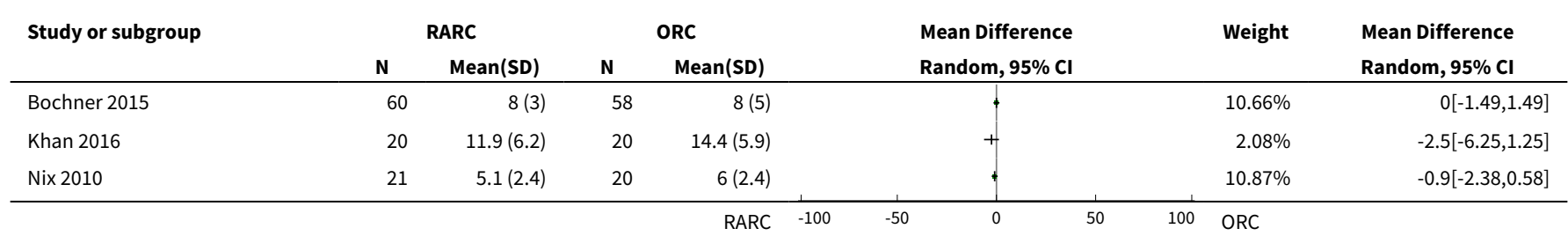




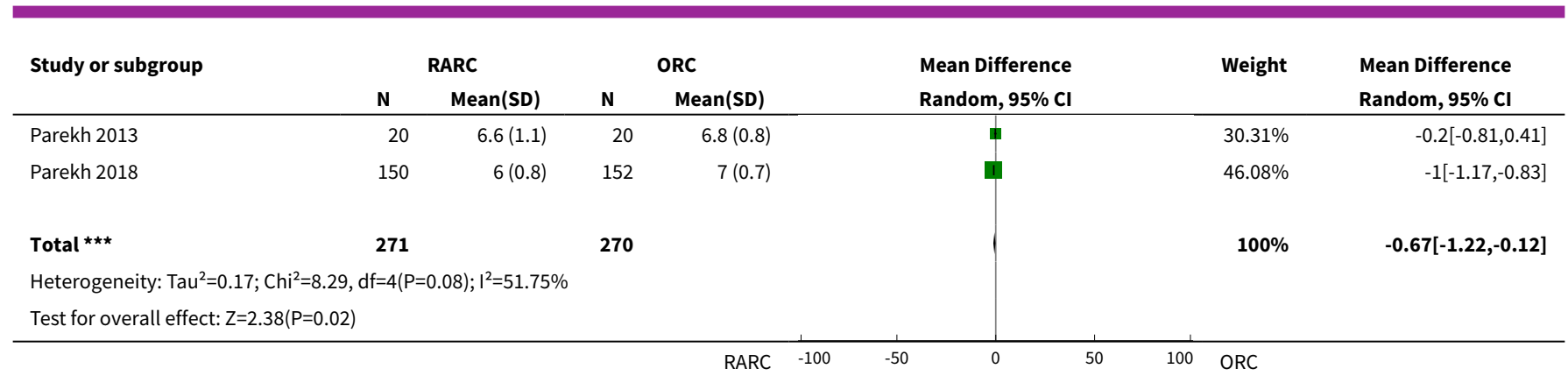

Analysis 1.6. Comparison 1 Robotic-assisted laparoscopic versus open radical cystectomy, Outcome 6 Quality of life.

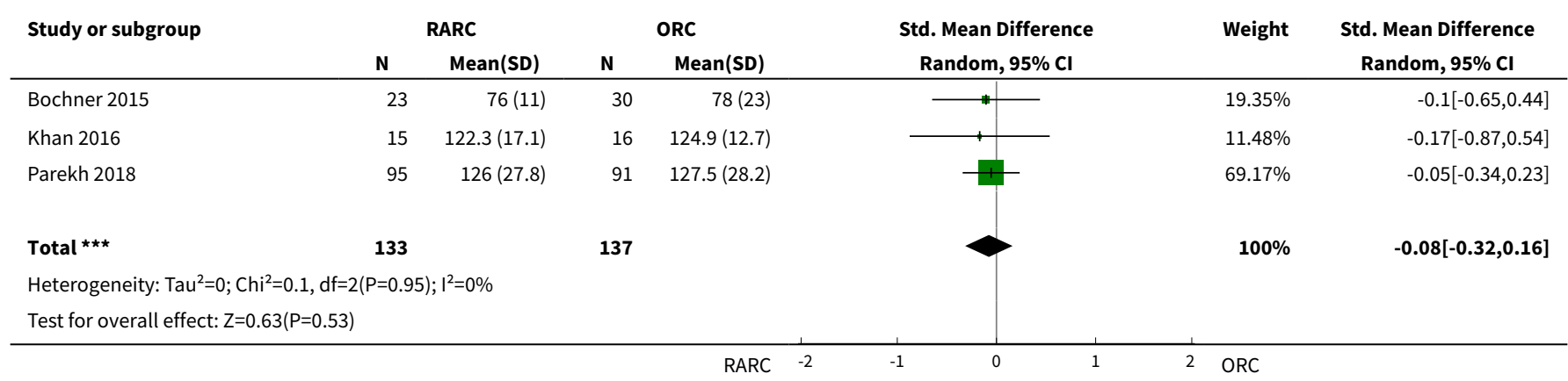

Analysis 1.7. Comparison 1 Robotic-assisted laparoscopic versus open radical cystectomy, Outcome 7 Positive margin.

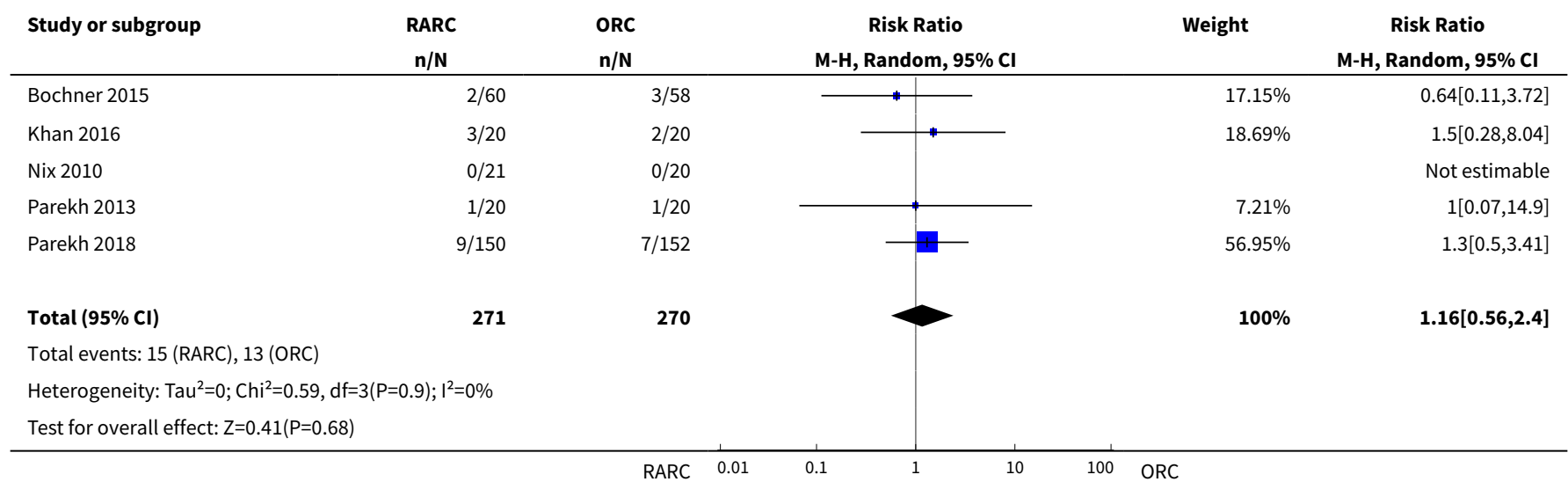

\section{APPENDICES}

Appendix 1. Electronic search strategies

\section{Database}

\section{Search terms}


(Continued)

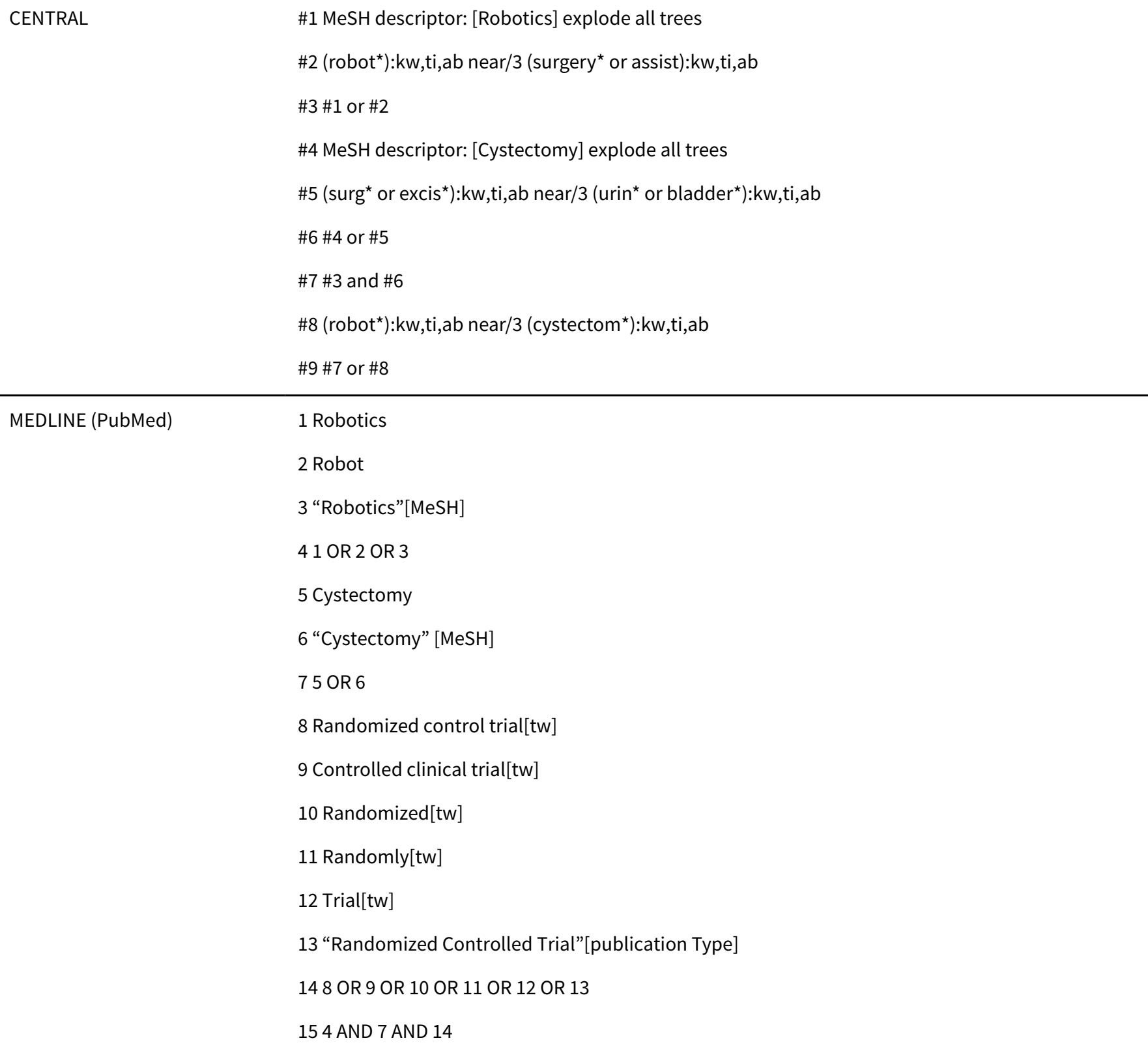

Embase (Ovid)

1. (cystectomy and controlled clinical trial and robotic).af.

2. (randomised controlled trial and robotic and cystectomy).af.

3. (cystectomy and robotic).af.

Web of Science

1. (TOPIC:(cystostomy) AND TOPIC: (robotic))

2. ((TOPIC:(cystostomy) AND TOPIC: (robotic))AND TOPIC: (randomizedcontrolled trial))

3. TITLE: (cystectomy) AND TITLE: (robotic) AND TITLE: (randomized controlled trial)

4. TITLE: (cystectomy) AND TITLE: (randomized controlled trial) 
(Continued)
Institute of Cancer Research
1. Bladder cancer trials
2. Robotic cystectomy

\begin{tabular}{ll}
\hline ClinicalTrials.gov & 1. robotic | bladder cancer | cystectomy | Child, Adult, Senior \\
2. robotic | Open Studies | bladder cancer | cystectomy
\end{tabular}

BioMed Central ISRCTN

1. robotic Remove filter within Condition: bladder cancer Remove filter Interventions: cystectomy Remove filter

\begin{tabular}{ll}
\hline WHO ICTRP & 1. bladder cancer AND cystectomy AND Robot \\
& 2. bladder cancer AND cystectomy AND Robot AND trial
\end{tabular}

Terms used robotic cystectomy

robot cystectomy

robot assisted cystectomy

robotic radical cystectomy

\section{CONTRIBUTIONS OF AUTHORS}

BR: wrote the review and contributed to data extraction and analysis, concept, and data interpretation.

JB: contributed to data extraction and analysis and drafting work.

NV: contributed to text of review and to data analysis, concept, and data interpretation.

JA: contributed to text of review and to data analysis, concept, and data interpretation.

TL: contributed to text of review and to data analysis, concept, and data interpretation.

KA: contributed to text of review and to concept.

MSK: contributed to text of review, concept, and data interpretation.

PD: contributed to text of review, concept, and data interpretation.

KG: contributed to text of review and to concept and data interpretation.

PLC: contributed to text of review and to interpretation of data and concept.

OMA: wrote the review and contributed to data extraction and analysis, concept, and data interpretation.

\section{DECLARATIONS OF INTEREST}

BR: none known.

JB: none known.

NV: none known.

JA: none known.

TL: none known.

KA: none known.

MSK: none known. 
PD: none known.

KG: none known.

PLC: none known.

OMA: none known.

\section{SOURCES OF SUPPORT}

\section{Internal sources}

- None, Other.

\section{External sources}

- None, Other.

DIFFERENCES BETWEEN PROTOCOL AND REVIEW

- None

\section{NOTES}

We have based parts of the Methods section of the protocol for this review on a standard template developed by the Cochrane Metabolic and Endocrine Disorders Group that has been modified and adapted for use by the Cochrane Urology Group.

\section{N DEX TERMS}

\section{Medical Subject Headings (MeSH)}

Cystectomy [*methods]; Postoperative Complications [epidemiology]; Quality of Life; Randomized Controlled Trials as Topic; Robotic Surgical Procedures [*methods]; Treatment Outcome; Urinary Bladder Neoplasms [ ${ }^{\star}$ surgery]

\section{MeSH check words}

Humans 